Seismic Determination of Reservoir Heterogeneity: Application to the Characterization of Heavy Oil Reservoirs

\author{
Annual Report \\ Report Period: 09/01/2002 - 08/31/2003 \\ Matthias G. Imhof \\ November 2003 \\ DE-FC26-00BC15301 \\ Matthias G. Imhof \\ Department of Geosciences \\ Virgina Tech \\ 4044 Derring Hall (0420) \\ Blacksburg, VA 24061 \\ James W. Castle \\ Department of Geological Sciences \\ Clemson University \\ 340 Brackett Hall \\ Clemson, SC 29634-0976
}




\section{Disclaimer}

This report was prepared as an account of work sponsored by an agency of the United States Government. Neither the United States Government nor any agency thereof, nor any of their employees, makes any warranty, express or implied, or assumes any legal liability or responsibility for the accuracy, completeness, or usefulness of any information, apparatus, product, or process disclosed, or represents that its use would not infringe privately owned rights. Reference herein to any specific commercial product, process, or service by trade name, trademark, manufacturer, or otherwise, does not necessarily constitute or imply its endorsement, recommendation, or favoring by the United States Government or any agency thereof. The views and opinions of authors expressed herein do not necessarily state or reflect those of the United States Government or any agency thereof. 


\section{Abstract}

The objective of the project is to examine how seismic and geologic data can be used to improve characterization of small-scale heterogeneity and their parameterization in reservoir models. The study is performed at West Coalinga Field in California.

We continued our investigation on the nature of seismic reflections from heterogeneous reservoirs. We began testing our algorithm to infer parameters of object-based reservoir models from seismic data. We began integration of seismic and geologic data to determine the deterministic limits of conventional seismic data interpretation. Lastly, we began integration of seismic and geologic heterogeneity using stochastic models conditioned both on wireline and seismic data. 


\section{Contents}

1 Introduction $\quad 5$

$\begin{array}{llr}2 & \text { Executive Summary } & 8\end{array}$

3 Cumulative Bibliography $\quad 9$

4 Results

$\begin{array}{ll}\text { Stratigraphic filtering } & \text { A1 }\end{array}$

$\begin{array}{ll}\text { Object-Based Stochastic Facies Inversion } & \text { B1 }\end{array}$

Deterministic High-Resolution Seismic Reservoir Characterization C1

Integration of Geologic Models and Seismic Data to Characterize Interwell

Heterogeneity of The Miocene Temblor Formation, Coalinga, California D1 


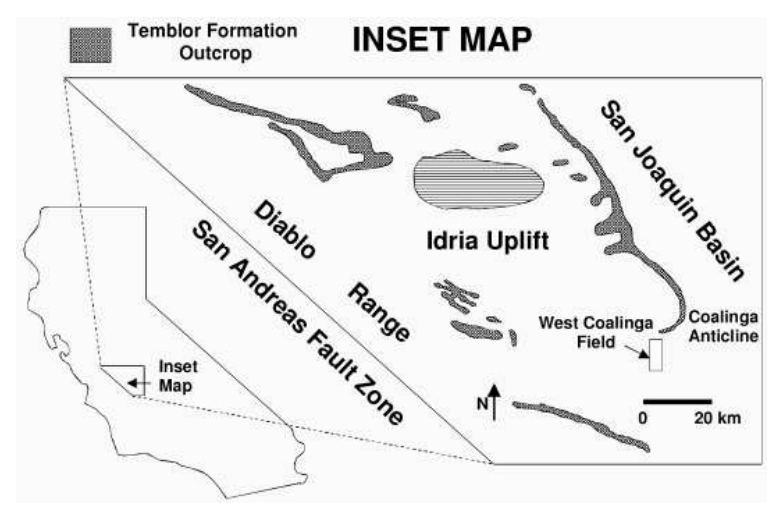

Figure 1: Location map of the Coalinga area, California.

\section{Introduction}

The objective of the project is to examine how seismic data can be used to parameterize models of small-scale reservoir heterogeneity. Although these heterogeneities cannot be resolved individually (deterministically) using seismic data, one can at least attempt to estimate their statistical properties from seismic data. Initially we planned to derive geological and geophysical heterogeneity models in an independent manner to allow comparison, but we came to believe that no single approach will suffice for the Coalinga field. Instead, geological and geophysical models need to be integrated early to succeed in complex environments.

Reservoir characterization is an essential step in delineation, development, and production of hydrocarbon reserves. Our test area, the giant Coalinga field in California's San Joaquin Valley, is a good example. Large-scale steam-flood projects have been utilized for many years in order to enhance recovery of heavier oil. Steam-floods are costly to operate due to the necessary infrastructure and their energy consumption. Optimally, injected steam would spread evenly from the injection point and push the oil toward the producer wells. In reality, the steam patterns are very complex. Reservoir characterization provides an improved understanding of the reservoir and the movement of steam, which will help to increase the profitability by reducing steam injection which decreases the environmental impact of steam injection. Reservoir heterogeneity affects not only the steam flood, but also the 
production. The Coalinga reservoirs are strongly compartmentalized which is aggravated by the high oil viscosity. Reservoir characterization helps siting infill wells to produce bypassed oil to increase ultimate recovery.

Knowing the details of the reservoir allows simulation of different injection or production scenarios. The problem, however, is to build an accurate and suitable reservoir model that includes small-scale heterogeneity. Locally, boreholes yield an excellent description of the vertical heterogeneity at different spatial scales ranging from centimeters to hundreds of meters. Most of the time, the lateral heterogeneity cannot be derived from well data because of the large distances between wells. The most abundant data are seismic data, but their resolution is only on the order of tens of meters which is typically insufficient to resolve geological heterogeneities. Features smaller than a seismic quarter wavelength cannot be resolved with certainty. Yet the geology exhibits many small-scale features which may have a pronounced effect on the reservoir. For example, a clay drape is invisible on the seismic data but poses an impenetrable barrier to steam and oil. By combining seismic and well data, a deterministic framework is traditionally constructed which contains the major stratigraphic features. Small-scale features are filled in using statistical methods conditioned to well data and outcrops. The parameters for the fill-in process are often provided by measurements of analogous outcropping formations, analogous mature reservoirs with a dense well spacing, horizontal wells, pressure and production tests, or simply by accepting the default parameters of the modeling packet.

The objective of the project is to examine how seismic and geologic data can be used to describe small-scale heterogeneity and parameterize the reservoir models. Although these heterogeneities cannot be resolved individually (deterministically) using seismic data, we attempt to estimate their statistics from seismic data. The Coalinga field contains more than 2000 wells which provide the unusual luxury that even small-scale heterogeneity can be characterized with well data. The site allows construction of reservoir models from either seismic data or wireline logs and outcrops. Since these data are independent, the models 
could be compared and validated against each other. No single heterogeneity model, however, can characterize the heterogeneity of Coalinga field. Instead, geologic and geophysical heterogeneity models need to be integrated early. 


\section{Executive Summary}

The objective of the project is to examine how seismic data can be used to improve characterization of small-scale heterogeneity and their parameterization in reservoir models. During the third year, we continued interpretation of the seismic poststack data, continued work on the nature of seismic reflections in heterogeneous media, began testing an inversion algorithm to estimate the parameters of reservoir models based on geometric objects from seismic data, and began to integrate heterogeneity models based on geologic and geophysical data.

We continued our investigation on the nature of seismic reflections from heterogeneous reservoirs and observed that short-scale heterogeneity puts its footprint on the energy spectra of transmitted and reflected waves.

Object-based reservoir models build realizations by emplacing geometric objects corresponding to channels, barriers, or sand sheets. Previously, we developed a new algorithm to estimate the object parameters from seismic data. We tested the algorithm with seismic field data, and are now in the process to improve the resulting heterogeneity model by simultaneously estimating the parameters and conditioning the realization on seismic and wireline data.

We tied the seismic data to wireline logs and mapped the four Temblor unconformities seismically. The seismic dataset is merged from numerous surveys which introduces many artificial discontinuities and wavelet changes. Mapping of reservoir elements required removal of these artifacts by iterative flattening on deeper seismic horizons to improve continuity. We began to use seismic volume visualization and geobody analysis to separate the reservoir into different sedimentary bodies and are now in the process of integrating all geologic and geophysical data to understand the lithologic and petrophysical meaning of seismic attributes.

Previously, we built stochastic models conditioned only on wireline and geologic data. In the past year, we began to further condition these realizations on seismic data.

In the fourth and final project year, we will integrate seismic and geologic data both deterministically and stochastically. 


\section{Cumulative Bibliography}

M. G. Imhof, 'The Heterogeneity Cube: a Family of Seismic Attributes', 71st Annual International Meeting of the Society of Exploration Geophysicists, San Antonio, 2001.

M. G. Imhof, 'The Heterogeneity Cube: a Family of Seismic Attributes', American Association of Petroleum Geologists Annual Convention, Houston, 2002.

M. G. Imhof, 'Estimation of 3D Reservoir Heterogeneity using Seismic Heterogeneity Cubes', 64th Meeting in Florence, European Association of Geoscientists \& Engineers, Extended Abstracts, 2002.

E. Nowak, M. G. Imhof, and W. Kempner, 'Object-Based Stochastic Facies Inversion: Application to the Characterization of Fluvial Reservoirs', 72nd Annual International Meeting of the Society of Exploration Geophysicists, Salt Lake City, 2002.

K. L. Mize, J. W. Castle, F. J. Molz, and M. G. Imhof, 'Integration of Stratigraphy and Seismic Geophysics for Improved Resolution of Subsurface Heterogeneity', Clemson University Tenth Annual Hydrogeology Symposium Abstracts with Program, April 2002, p. 28.

K. L. Mize, 'Development of Three-Dimensional Geological Modeling Methods using Cores and Geophysical Logs, West Coalinga Field, California', MS Thesis, Clemson University, 2002.

M. G. Imhof, 'Scale Dependence of Reflection and Transmission Coefficients', Geophysics, 68(1), 322-336, 2003.

M. G. Imhof and W. Kempner, 'Seismic Heterogeneity Cubes and Corresponding Equiprobable Simulations', Journal of Seismic Exploration, 12(1), 1-16, 2003.

J. L. Piver, J. W. Castle, M. T. Poole, R. A. Hodges, and M. G. Imhof, 'Integrating Geologic Models and Seismic Data to Characterize Interwell Heterogeneity of the Miocene Temblor 
Formation, Coalinga, California', Geological Society of America Abstracts with Programs, March 2003, v. 35, no. 1, p. 54.

J. L. Piver, J. W. Castle, M. T. Poole, R. A. Hodges, and M. G. Imhof, 'Characterization of Stratigraphic Heterogeneity in the Temblor Formation (Miocene), Coalinga Area, California: Integration of Geologic Models and Seismic Geophysical Data', Clemson University Eleventh Annual Hydrogeology Symposium Abstracts with Program, April 2003, p. 20.

M. G. Imhof and W. C. Kempner, 'Seismic Heterogeneity Cubes and Corresponding Equiprobable Simulations', American Association of Petroleum Geologists Annual Convention, Salt Lake City, 2003.

S. Mahapatra, M. G. Imhof, and W. C. Kempner, 'Deterministic High-Resolution Seismic Reservoir Characterization', American Association of Petroleum Geologists Annual Convention, Salt Lake City, 2003.

M. G. Imhof, 'Equiprobable Simulations of Seismic Heterogeneity Cubes', 65th Meeting of the European Association of Geoscientists \& Engineers, Stavanger, 2003.

M. G. Imhof, 'Seismic Heterogeneity Cubes and Corresponding Equiprobable Simulations', Interpreting Reservoir Architecture Using Scale-Frequency Phenomena, Oklahoma Geolocial Society and National Energy Technology Laboratory, Oklahoma City, 2003. 


\title{
Stratigraphic filtering
}

\author{
Ethan J. Nowak and Matthias G. Imhof
}

\begin{abstract}
A seismic pulse propagating through a material exhibiting a set or sets of thin periodic layers undergoes a predictable regiment of wavelet shapening. This phenomenon is commonly known as stratigraphic filtering. Numerical modeling of acoustic wave propagation suggests that the sinusoidal components of the incident signal with a wavelength that corresponds to the periodicity of the material be preferentially reflected. This preferential reflection of sinusoids renders a relatively narrow bandwidth of elevated energy corresponding with the periodicity of the material. In addition, the spectral bandwidth of these anomalies is directly proportional to the layer thickness used to establish the material periodicity. Isolating the different portions of the reflected wavefield and calculating the Fourier energy spectra may provide evidence of thin periodic layers which are deterministically unresolvable.
\end{abstract}

\section{Introduction}

Stratigraphic filtering is a phenomenon that has been reported by numerous authors (O'Doherty and Anstey, 1971; Banik et al., 1985b,a). In general, this phenomenon is observed in reflected and transmitted wavefields as a signal propagates through a material exhibiting thin periodic lamina or layers. In this context, thin refers to the thickness of the individual layers when deterministically unresolvable by a reflection (i.e. $<\frac{1}{4}$ wavelength, $\lambda$ ). When 
the direction of propagation is perpendicular to the layering the material acts as a frequency filter that alters the shape of the reflected and transmitted signal. The shapening of these signals, caused by the filter, is due to the amplification or attenuation of certain sinusoidal components of the incident signal. Deng (1994) reported that for a normal incident seismic signal propagating through thin periodic layers, the interference of short-period multiples attenuates the high frequencies of the transmitted signal. Signals propagating obliquely to layering may experience an additional loss of high frequencies through evanescent filtering, a

phenomenon caused by the preferential tunneling of lower frequencies within higher velocity thin layers.

We propose an alternative explanation for the cause of stratigraphic filtering and examine which information can be derived from this phenomenon. Both an analytical solution and numerical modeling of zero-offset acoustic wave propagation were used to investigate the cause of this phenomenon. The analytical solution was facilitated by an acoustic layer stack scheme (Imhof, 2003), which allows direct calculation of the reflection and transmission coefficients. The numerical modeling technique is based on a space-time finite difference approximation to the scalar wave equation (Jensen et al., 1994), which provides a means of calculating the reflected and transmitted wavefields. Wavefields and spectra were calculated for layer stacks of various layer thicknesses and periodicities.

Before discussing the topic of stratigraphic filtering, it may be useful to outline a possible mathematical analogy, namely Bragg scattering or Bragg reflection, that can be used to describe the phenomenon of waves propagating in periodic media.

\section{Bragg scattering}

When considering plane wave propagation along a linear, elastic, homogeneous, isotropic, and periodic, lattice as depicted in the 1-D model of nodes shown in Figure 1, a phenomenon termed Bragg scattering can be observed. 


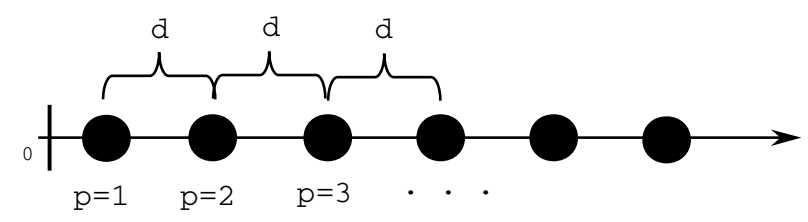

Figure 1: 1-D model of $\mathrm{n}$ nodes separated by a distance $d$ where each node is characterized by the same acoustic velocity and identified by the integer $p$.

Bragg scattering is the result of a plane wave propagating at a particular wavenumber $k$. To illustrate this phenomenon, consider the following 1-D scalar wave equation

$$
\frac{d^{2} U}{d t^{2}}=\frac{E}{\rho} \frac{d^{2} U}{d x^{2}}
$$

where $E$ and $\rho$ denote a constant Young's modulus and density on the lattice with a node spacing $d$. The spatial derivative with respect to displacement $U$ on the right hand side can be rewritten as a differencing equation of order two:

$$
\frac{d^{2} U}{d t^{2}}=\frac{E}{\rho d^{2}}\left(U_{p+1}+U_{p-1}-2 U_{p}\right)
$$

where $p$ refers to the node index. Assuming plane wave displacements

$$
U=A e^{i(k p d-\omega t)}
$$

where $A$ denotes a constant amplitude, $\omega$ refers to angular frequency, and distance $x=p d$ and substituting (3) into (2), evaluating the temporal derivative, and utilizing Euler's relationship $e^{i \alpha}=\cos \alpha+i \sin \alpha$ yields the dispersion relation

$$
\omega(k)=\frac{2}{d} \sqrt{\frac{E}{\rho}} \sin \frac{k d}{2} .
$$

Group velocity descibes the speed with which energy propagates as a function of $k$. It is calculated by differentiating the dispersion relation (4) with respect to wavenumber: 


$$
v_{G}=\frac{d \omega(k)}{d k}=\sqrt{\frac{E}{\rho}} \cos \frac{k d}{2} .
$$

This group velocity $v_{G}(k)$ exhibits two different behavoirs. As can be seen from equation (5), the case where $k>\pi / d$ results in a negative group velocity, which corresponds to ultimate dispersion where the signal is incapable of penetrating the lattice. For the case where $k<\pi / d$, the group velocity attains a positive value and the signal propagates along the lattice without distortion. At the threshold $k=\pi / d$, the group velocity is zero which corresponds to a standing wave (Sheng, 1995). This latter case is the Bragg scattering phenomenon. This effect dictates the high-frequency limit of wave propagation on a lattice, but the typical frequencies utilized in geophysical studies do not approach this limit. By using this Bragg scattering analogy and introducing 1-D periodic heterogeneity to the model, the stratigraphic filtering phenomenon may be explained.

\section{Stratigraphic filtering}

Stratigraphic filtering is a phenomenon that has received much attention in seismic reservoir characterization studies. To explore its cause, consider the addition of a material periodicity to the 1-D model as shown in Figure 2.

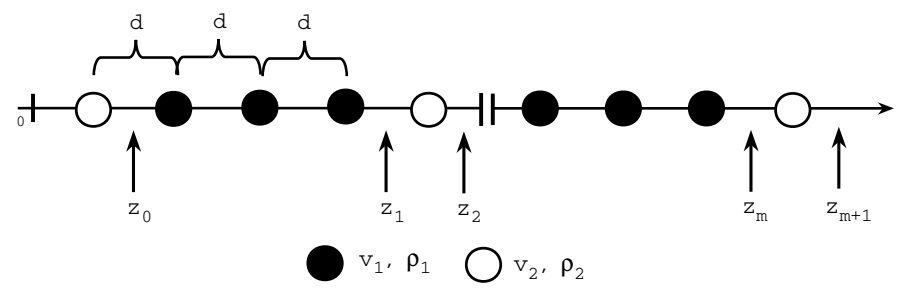

Figure 2: 1-D model of nodes separated by the distance $d$ exhibiting a material periodicity introduced by systematic changes in acoustic velocity $v$. The locations $z_{i}$ separate the different homogeneous zones within the lattice. 
With the introduction of the material periodicity to the 1-D model, difficulties arise when attempting to achieve a solution similar to the mathematical Bragg scattering analogy. However, it can be described analytically by an acoustic layer stack scheme or numerically by a space-time finite difference approximation to the scalar wave equation.

\section{Analytical solution}

The layer stack technique allows for the direct calculation of the reflection $R(\omega)$ and transmission $T(\omega)$ spectra produced by a plane wave propagating through a stack of layers with equivalent geometry to the one shown in Figure 2. A propagator matrix $\mathbf{P}_{\ell}$

$$
\mathbf{P}_{\ell}=\left[\begin{array}{cc}
e^{+i \omega\left(z_{\ell+1}-z_{\ell}\right) / v_{\ell+1}} & 0 \\
0 & e^{-i \omega\left(z_{\ell+1}-z_{\ell}\right) / v_{\ell+1}}
\end{array}\right]
$$

is used to extrapolate the waves from an interface $\ell$ at depth $z_{\ell}$ to interface $\ell+1$ at depth $z_{\ell+1}$ and vice versa. A transition matrix $\mathbf{V}_{\ell}$

$$
\mathbf{V}_{\ell}=\frac{1}{2}\left[\begin{array}{cc}
1+\xi_{(\ell+1) \ell} & 1-\xi_{(\ell+1) \ell} \\
1-\xi_{(\ell+1) \ell} & 1+\xi_{(\ell+1) \ell}
\end{array}\right] \quad \text { where } \quad \xi_{i j}=\frac{\rho_{i} v_{i}}{\rho_{j} v_{j}}
$$

based on the impedance ratios between adjacent layers governs the behavior of the plane waves propagating at the interface between layers $\ell$ and $\ell+1$. Thus, reflection $R(\omega)$ and transmission $T(\omega)$ coefficients for the entire layer stack can be directly calculated by coupling the propagator and transition matrices

$$
\left[\begin{array}{c}
0 \\
T(\omega)
\end{array}\right]=\mathbf{V}_{m} \cdot\left\{\prod_{\ell=0}^{m-1} \mathbf{P}_{\ell} \cdot \mathbf{V}_{\ell}\right\} \cdot\left[\begin{array}{c}
R(\omega) \\
1
\end{array}\right]
$$

The accuracy and numerical stability of the matrix product equation (8) can be tested by considering the conservation of energy $|R(\omega)|^{2}+\left.\xi_{0 n} T(\omega)\right|^{2}=1$ (Imhof, 2003).

As an example, the reflection and transmission coefficients were calculated for a layer 
stack consisting of alternating layers with thicknesses of 2 and $34 \mathrm{ft}$ and velocities 6250 and $5000 \mathrm{ft} / \mathrm{s}$, respectively. For simplicity, the density remained constant and was set to one. In this example, the layer stack exhibits a spatial periodicity of $36 \mathrm{ft}$ which corresponds to a temporal periodicity on the order of $0.0142 \mathrm{~s}$ or a material frequency of $70 \mathrm{~Hz}$. This material frequency is defined by the inverse Wyllie time average

$$
f_{\text {material }}=\left(\sum_{\ell=1}^{m} \frac{h_{\ell}}{v_{\ell}}\right)^{-1}
$$

modified from Wyllie et al. (1957), over a single spatial period of the layer stack. In this expression, $h_{\ell}$ and $v_{\ell}$ denote the thickness and velocity of the $\ell^{\text {th }}$ layer.

This material frequency establishes a fundamental frequency or resonance which corresponds to the first major peak on the reflected energy spectrum shown in Figure 3(a) and the first major trough on the transmitted energy spectrum shown in Figure 3(b). Note the frequencies associated with the integral multiples of the fundamental frequency (harmonic series) correspond to major troughs and peaks on the transmitted and reflected energy spectra. Which indicates that the sinusoidal components of the incident signal corresponding to the spatial periodicity of the material are preferentially reflected and hindered from propagating through the material.

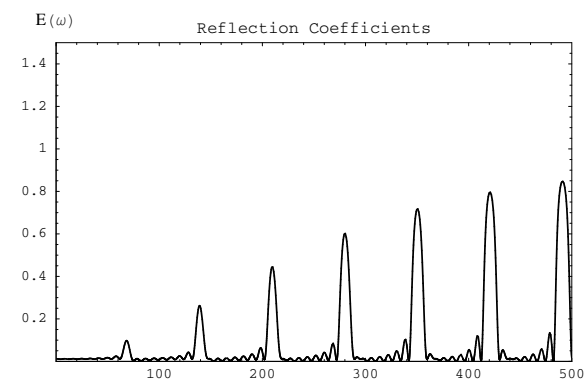

(a)

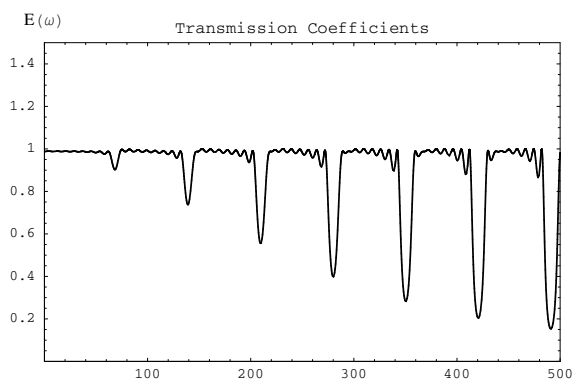

(b)

Figure 3: The energy spectra for the (a) reflection and (b) transmission coefficients. 


\section{Numerical solution}

This preferential reflection anomaly from the periodic layer stack can be confirmed with a numerical solution computed with a space-time finite difference approximation to the scalar wave equation. Figure 4(b) depicts the reflected wavefield response to propagating a Ricker wavelet with a $60 \mathrm{~Hz}$ center frequency through the 1-D velocity model shown in Figure 4(a). For comparision purposes, this velocity model is shown as a function of two way traveltime and is equivalent to the model previously shown in Figure 2.

As expected, the reflection from the top and bottom of the initial layer can be identified by wavelets with zero and $180^{\circ}$ phases shown in red and green, which correspond to the skewed Gaussian energy spectra depicted in Figures 5(a) and 5(b). The reflected wavefield from the periodic layers (shown in blue) rendered little deterministic resolution of the periodic thin layers. Because the thickness of the thin layers used to establish the periodic heterogeneity were less than $\frac{\lambda}{4}$ their interfaces were not resolvable by a reflected Ricker wavelet. However, the response of propagating the wavelet through the layer stack produce a sinusoidal reflection. This sinusoidal reflection is represented as a narrow peak of elevated energy as shown on Figure 5(c). This coda-like reflection is followed by another zero phase wavelet including a small amplitude sinusoidal trail (shown in black) reflected from the base of the layer stack. This basal reflection is characterized by a skewed Gaussian energy spectrum (i.e. similar to those depicted in Figures 5(a) and 5(b)), however containing a narrow trough of reduced energy as shown on Figure 5(d).

As in the previous discussion, the energy peak located at $70 \mathrm{~Hz}$ in Figure 5(c) coincides with the inverse Wyllie time average over one spatial period of the material. This observation not only confirms the preferential reflection of the sinusoidal components of the incident signal that corresponds to the periodicity of the material, but also suggests that the inverse Wyllie time average is a suitable estimator of this material frequency. Note the energy scale

on Figure 5(c) is approximately 33 times larger than that of the other energy spectra shown 
in Figure 5.

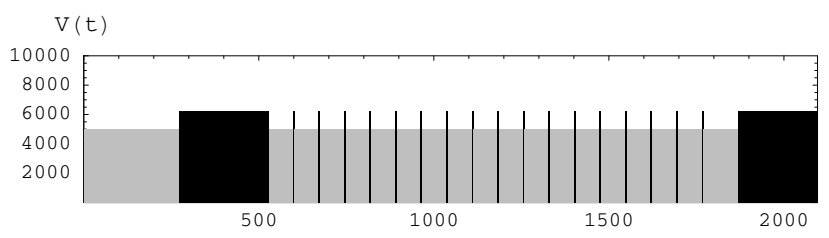

(a)

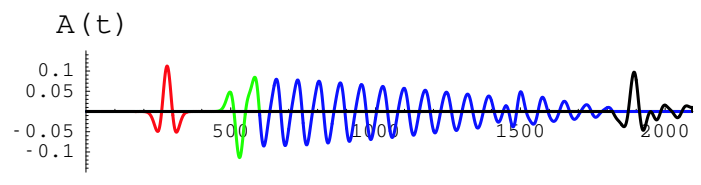

(b)

Figure 4: 1-D velocity model containing a periodic layer stack (a) and the reflected wavefield (b) showing the windows used to calculate the energy spectra shown in Figure 5.

Again, the frequencies associated with elevated reflected energy coincide with reduced transmitted energy as depicted on Figure 6. The accuracy and numerical stability of the finite differencing scheme can be tested by considering the conservation of energy, $|R(\omega)|^{2}+$ $\xi_{0 n}|T(\omega)|^{2}=|I(\omega)|^{2}$

\section{Discussion}

The narrow band or bands of reduced energy observed on Figures 5(d) and 3(b) and on the transmitted energy spectrum shown on Figure 6 are the result of frequency filtering the signal as it propagates through the layer stack. The stratigraphic filtering or any frequency filtering process is described as a time domain convolution of an input signal with a filter function which corresponds to a multiplication of their spectra in the frequency domain. Therefore, the narrow band of reduced energy observed on Figure 5(d) and the corresponding reflection from the base of the layer stack (shown in black on Figure 4(b)) can be explained by the following Fourier-time pairs shown in Figure 7. 


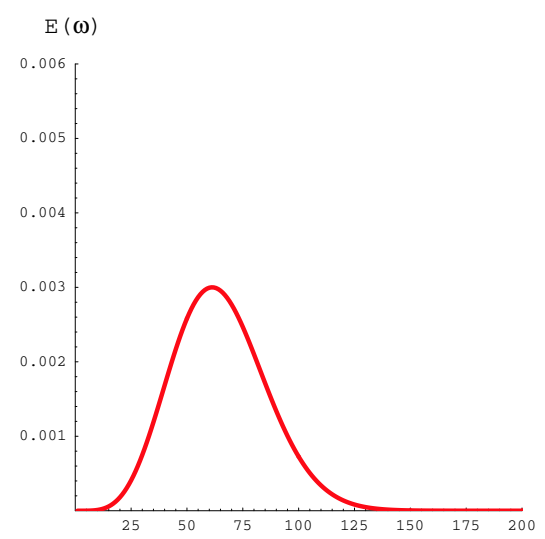

(a)

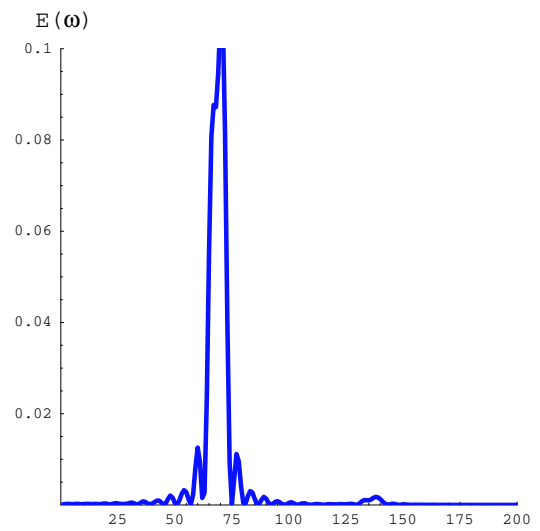

(c)

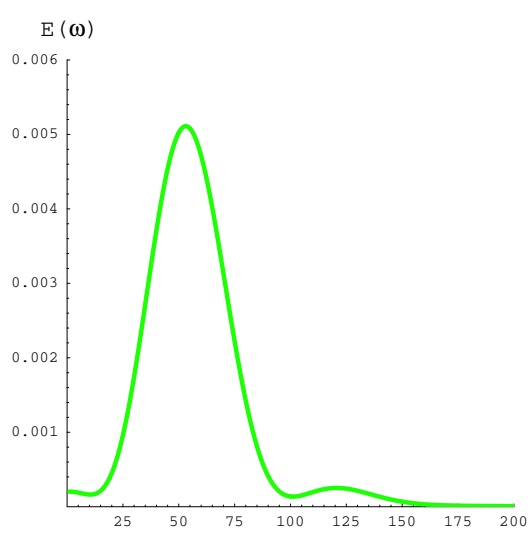

(b)

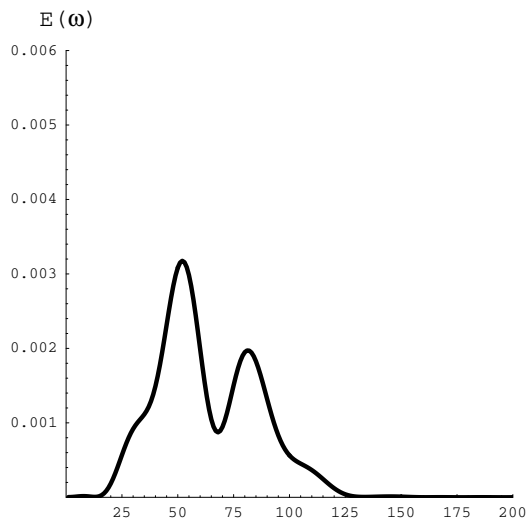

(d)

Figure 5: The energy spectra resulting from (a) the top of the initial layer, (b) base of the initial layer, (c) the layer stack, and (d) base of the layer stack.

The resultant Fourier spectrum produced by the multiplication of the incident and filter spectra of the Fourier-time pairs shown in Figure 7 resembles that of the spectum depicted in Figure 5(d). Similarly, the waveform produced by the convolution of the incident signal and the filter function resembles the reflected wavefield within the window used to calculate the energy spectrum shown in Figure 5(d).

These frequency dependent amplitude reductions also reported by Deng (1994), can only be observed by including the sinuous trail within the window for calculating the energy spectrum. The filtering process effects the shape of the transmitted and reflected wavelets. 


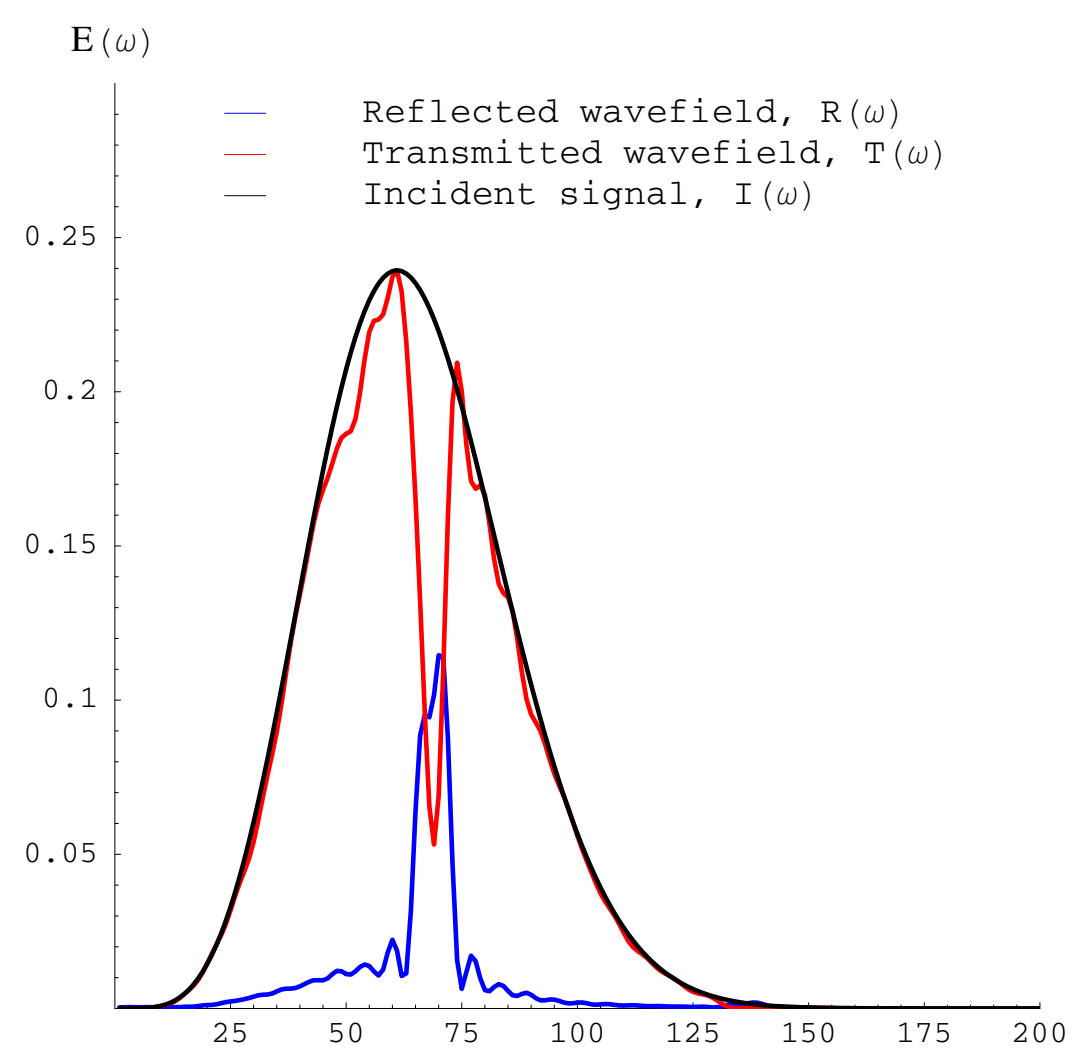

Figure 6: The calculated energy spectra for the entire reflected and transmitted wavefields and the incident signal.

This wavelet shapening depicted in Figure 7 is caused by the reduction or removal of a single frequency or a band of Fourier coefficients from the incident signal. To restore the shape of the incident signal, the reduced or removed frequencies need to be boosted or added back to the spectrum. Hence the removal of frequencies from a signal has the effect of introducing those frequencies with opposite polarity in the time domain wave form, thus the sinuous trail predominately consists of $70 \mathrm{~Hz}$ energy as depicted on Figure 7. Omitting the sinuous trail from the window used to calculate the energy spectrum has the same effect as removing the shapening caused by the filter as shown in Figure 7 .

The stratigraphic filtering phenomenon can be explored further by adjusting the thick- 

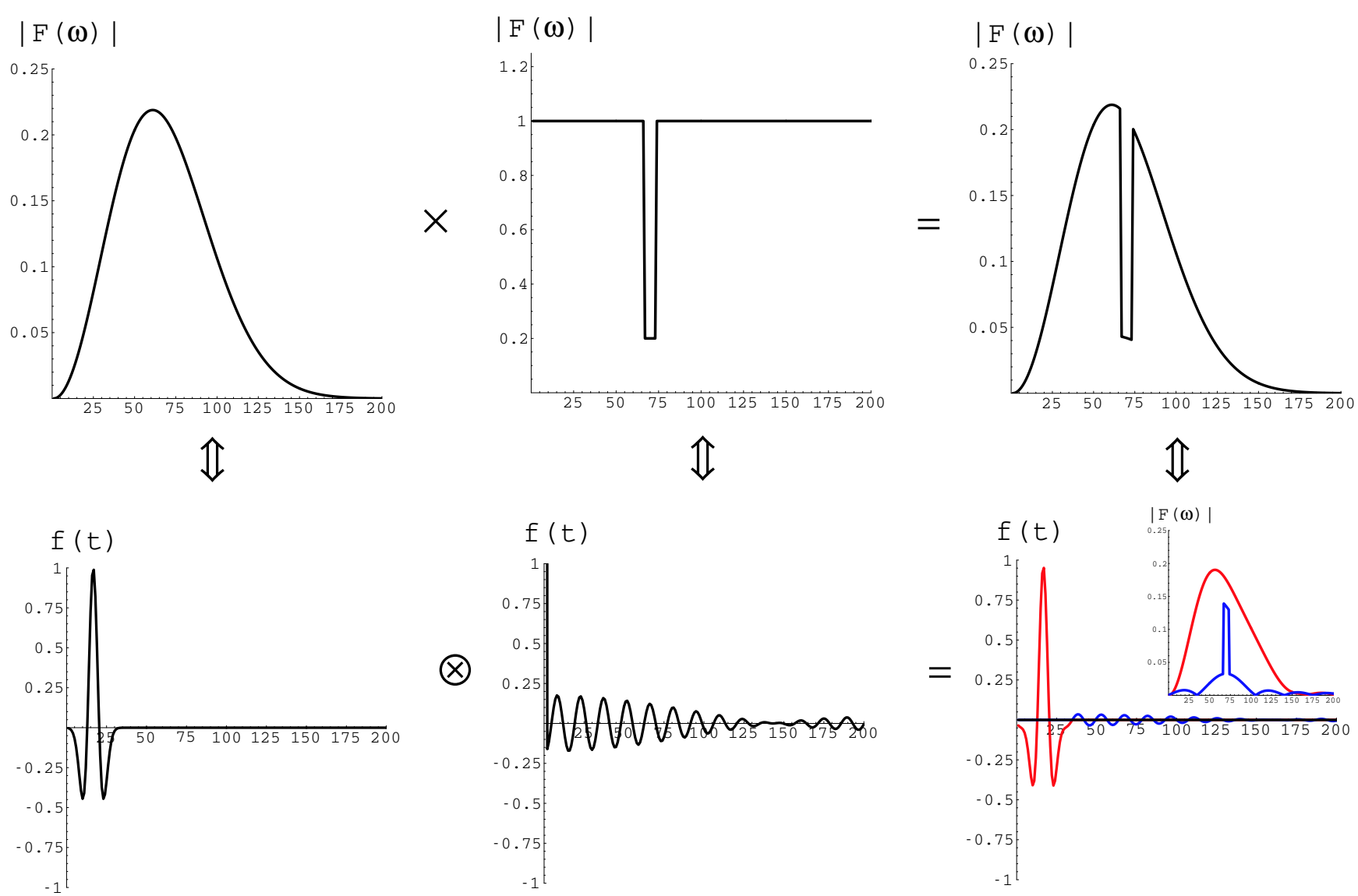

Figure 7: Fourier-time pairs depicting the filting process. Note the $70 \mathrm{~Hz}$ trail observed in the resultant time-domian waveform due to the $70 \mathrm{~Hz}$ filter.

nesses of the layers contained in the stack while preserving the natural resonance frequency of the material. The models were chosen such that the material frequency of the layer stack remained constant at $70 \mathrm{~Hz}$. However, the thickness, $h_{1}$, of the layers characterized by a velocity $v_{1}=6250 \mathrm{ft} / \mathrm{s}$ was increased from 2 to $46 \mathrm{ft}$ while the thickness, $h_{2}$, of the layers characterized by a velocity $v_{2}=5000 \mathrm{ft} / \mathrm{s}$ was decreased accordingly to comply with equation (9). As can be seen on Figure 8, the frequency corresponding to the mean energy remained relatively constant, which confirms that the inverse Wyllie time average over one spatial period of the material is a suitable estimator for the resonance frequency of this material.

The thickness of the layers used to establish the periodicity of the layer stack could be 


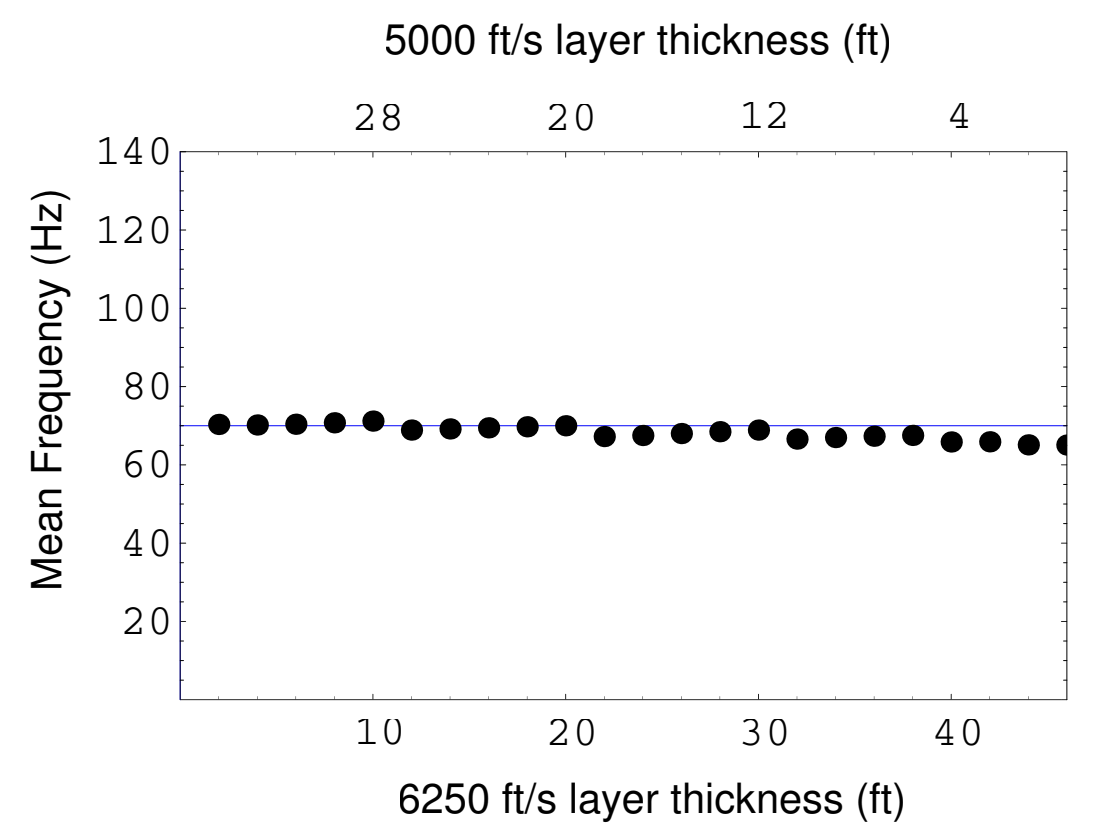

Figure 8: Cross-plot showing mean frequency as a function of varying layer thicknesses calculated from their Fourier derived energy spectra.

recovered qualitatively by calculating the bandwidth (Cohen, 1995) of the Fourier energy spectra. The cross-plot shown in Figure 9 depicts the bandwidth of the energy spectra generated for the previously described suite of models. By increasing one layer thickness and decreasing the other to maintain the same material frequency, the bandwidth of the energy spectra increases to a maxima. This maxima occurs when the travel time through the two layers is approximately the same. For this example, the threshold occurs when the thickness of the $6250 \mathrm{ft} / \mathrm{s}$ layer is $22 \mathrm{ft}$ and the $5000 \mathrm{ft} / \mathrm{s}$ layer is $18 \mathrm{ft}$ thick. Beyond this threshhold, the bandwidth decreases again.

\section{Conclusion}

Effects of stratigraphic filtering were explored by adding a material periodicity to the 1-D model. The results of the analytical solution and numerical modeling indicate that the sinusoidal components of the incident signal resonating with the periodicity of the material 


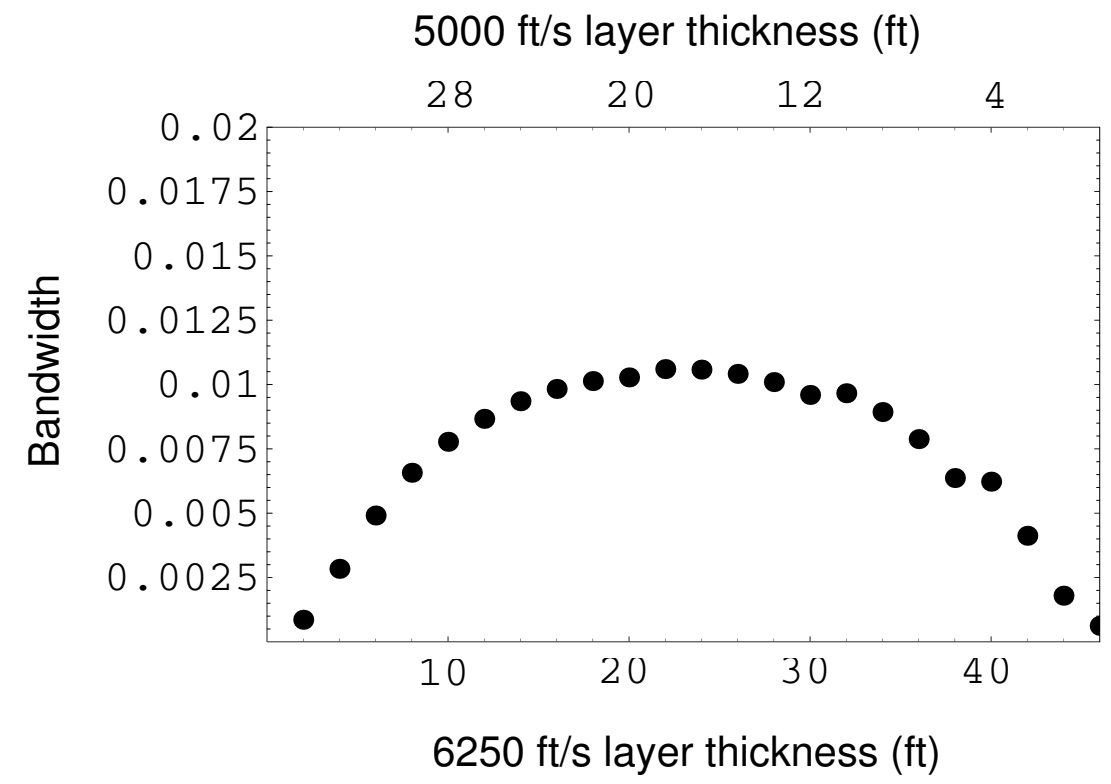

Figure 9: Cross-plot showing varying layer thicknesses as a function of bandwidth calculated from their Fourier derived energy spectra.

are preferentially reflected as opposed to attenuated by the interference of short period multiples. These preferentially reflected sinusoids are contained in a relatively narrow frequency band. These frequency bands of elevated elevated energy coincides with the inverse Wyllie time average of the material over a single spatial period, where as the bandwidth of the peaks is proportional to the relative traveltime thickness of the layers used to establish the periodicity of the material.

\section{References}

N. C. Banik, I. Lerche, J. R. Resnick, and R. T. Shuey. Stratigraphic filtering, part 2: Model spectra. Geophysics, 50:2775-2783, 1985a.

N. C. Banik, I. Lerche, and R. T. Shuey. Stratigraphic filtering, part 1: Derivation of the O’Doherty-Anstey formula. Geophysics, 50:2768-2774, 1985b.

Leon Cohen. Time-frequency analysis. Prentice Hall, Englewood Cliffs, New Jersey, 1995. 
H. Lydia Deng. Acoustic wave propagation in thin layered media with steep reflectors. Geophysics, 59:1593-1604, 1994.

Matthias G. Imhof. Scale dependence of reflection and transmission coefficients. Geophysics, 68:322-336, 2003.

F. B. Jensen, W. A. Kuperman, M. B. Porter, and H. Schmidt. Computational Ocean Acoustics. American Institute of Physics, Woodbury, New York, 1994.

R. F. O'Doherty and N. A. Anstey. Refections on amplitudes. Geophysical Prosecting, 55: 1158-1165, 1971.

Ping Sheng. Introduction to wave scattering, localization, and mesoscopic phenomena. Academic Press, Inc, San Diego, California, 1995.

Robert E. Sheriff and Lloyed P. Geldart. Exploration Seismology. Cambridge University Press, New York, New York, 1995.

M. R. J. Wyllie, A. R. Gregory, and G. H. F. Gardner. An experimental investigation of factors affecting elastic wave velocities in porous media. Geophysics, 23:459-493, 1957.

\section{APPENDIX}

\section{SUMMARY OF CALCULATIONS}

The seismic waves were modeled by a 1-D space-time finite difference approximation to the scalar wave equation which can written as

$$
\frac{d^{2}}{d x^{2}} U(x, t)+\frac{1}{c(x)} \frac{d^{2}}{d t^{2}} U(x, t)+S(x, t)=0,
$$


where $c(x)$ is acoustic velocity, $U(x, t)$ refers to a displacement-time function, and $S(x, t)$ denotes a source-time function all located at $x$. The wave equation can be discritized using spatial and temporal steps $h$ and $k$ :

$$
\frac{1}{h^{2}}\left(U_{i-1}^{n}+U_{i+1}^{n}\right)-\frac{1}{k^{2} c_{i}^{2}}\left(U_{i}^{n-1}-2 U_{i}^{n}+U_{i}^{n+1}\right)+S_{i}^{n}=0
$$

where $U_{i}^{n}$ denotes $U(x=i h, t=n k)$ and $S_{i}^{n}$ is give by a Ricker wavelet acting at a constant spatial position $i_{c}$

$$
S_{i_{c}}^{n}=\left\{1-2 \pi^{2} f_{c}^{2}\left(n k-t_{s}\right)^{2}\right\} e^{-\pi^{2}(n k-t s)^{2} f_{c}^{2}}
$$

where $f_{c}$ is the center frequency and $t_{s}$ is a time shift typically greater than $\frac{1}{f_{c}}$ to enforce causality modified from Sheriff and Geldart (1995). If $U^{n-1}$ and $U^{n}$ are known $U^{n+1}$ can be predicted by:

$$
U^{n+1}=\left(\frac{c_{i} k}{h}\right)^{2}\left(U_{i-1}^{n}-2 U_{i}^{n}+U_{i+1}^{n}\right)+\left(U_{i}^{n-1}-2 U_{i}^{n}\right)+\left(S_{i}^{n}-S_{i}^{n-1}\right)
$$

Note that for stability reasons $\frac{c_{i} k}{h}<1$ (Jensen et al., 1994).

From the definition of the forward Fourier transform

$$
F(\omega)=\int f(t) e^{i \omega t} d t
$$

the energy spectrum is calculated by

$$
E(\omega)=|F(\omega)|^{2}=F(\omega) F^{*}(\omega)
$$

where $*$ denotes complex conjugate. From equation (15), the mean frequency

$$
\bar{\omega}=\int \omega E(\omega) d \omega
$$


and bandwidth

$$
B^{2}=\int(\omega-\bar{\omega})^{2} E(\omega) d \omega
$$

can be calculated (Cohen, 1995). 


\title{
Object-Based Stochastic Facies Inversion
}

\author{
Ethan J. Nowak and Matthias G. Imhof
}

\begin{abstract}
This study is focused on introducing and assessing an adaptation to conventional techniques to generate reservoir realizations of hydrocarbon reservoirs. Some conventional techniques of stochastic reservoir modeling incorporate the use of lithology logs, reservoir statistics, architectural element analysis, deterministic seismic interpretation, geologic intuition, and modern/ancient analogs. The aim of the object-based stochastic facies inversion is to define the parameters currently derived from geologic intuition and analogs through a simulated annealing guided search technique for waveform inversion.
\end{abstract}

\section{Introduction}

Reservoir models are a necessary tool during the exploitation of hydrocarbon reservoirs. Such realizations may be generated by defining the model and its parameters that dictate the composition and internal structure of a reservoir. Core and wireline log data provide a detailed account of the lithologic composition of a reservoir and are capable of identifying small-scale heterogeneities at the well locations. Because these data are incapable of resolving features that deviate from the well path, log correlation and deterministic seismic interpretations are often used to interpolate between wells. The seismic reflection interpretations provide a means of resolving lateral and vertical heterogeneity between wells, but 
are subject to a $\frac{1}{4}$ wavelength resolution limit. Due to resolution limits of deterministic seismic interpretations and the one dimensional nature of core and wireline log data, conventional techniques of generating reservoir models rely on geologic intuition and modern or outcrop analogs to further characterize a reservoir. For example, to characterize a reservoir exhibiting channelized features, geologic intuition and analogs aid in defining the sinuosity of small-scale channels, width-to-depth ratios of associated facies, and how these associated facies are positioned spatially with respect to one another.

Object-based reservoir models build a realization by emplacing channels, barriers, and other objects using parameters such as sinuosity and aspect ratios. The purpose of the object-based stochastic facies inversion is to reduce the dependence on geologic intuition and analogs when generating realizations of hydrocarbon reservoirs. We are working on an object-based stochastic facies inversion, which determines model parameters and their ranges from all available data, including seismics. The inversion process begins with an initial reservoir realization, which is converted to seismic velocity and density, and used to calculate synthetic seismic data. The synthetic seismic data is compared to the observed seismic data. Based on this comparison, a new set of parameters are chosen which are consistent with all other data. The new set of parameters is used in the object-based reservoir simulation to generate a new realization, which is conditioned to the well logs. This iterative process continues until an acceptable match between the realization and data is attained.

We believe that a more quantitative approach to defining these parameters will generate reservoir models with improved correlation between predicted and recorded production histories.

\section{Methodology}

\section{Object-based stochastic reservoir modeling}

The process of generating a reservoir realization through an object-based stochastic pro- 
cess is a function of several statistical parameters. These parameters typically include, but are not limited to: mean width, thickness, and length of the included objects, standard deviations associated with these aspect ratios, volumetric proportions of the included objects, mean amplitudes and sinuosity of channels, and rules governing how these objects are positioned spatially with respect to one another. The objects included in the modeling process are typically geometric shapes of geologic significance, such as half elipsoids, domes, prisms, and rectangular cubes representing channels, bars or dunes, splays, and barriers.

The stochastic process initiates by pseudo-randomly emplacing the objects based on their respective statistical parameters (mean and variance values) within a model space. If this realization honors the volumetric proportions of the included objects within some degree of tolerance and predefined interval facies logs, the realization is accepted. However, if the realization does not honor these parameters, which are derived solely on core and wireline log interpretation, subsequent realizations are generated until the geologic criterion is achieved.

The volumetric proportion of objects can be determined from the core and wireline log data, however the remaining statistical parameters (mean and variance of the aspect ratios associated with the objects, mean amplitudes and sinuosity of channel systems, and the location rules) need to be defined.

\section{Inversion}

In principle, the statistics of the architectural objects and the location rules can be determined from observed seismic data by nonlinear inversion, however the nonlinearities are strong enough that a linearized least-squares inversion would probably not find the optimum model. In this study, we employ a guided search technique for nonlinear inversion, simulated annealing (SA), to determine the optimal solution for the model parameters.

The simulated annealing algorithm is employed to find a model $\mathbf{m}$ that minimizes a normalized error-energy function $E$ or maximizes a cross-correlation between observed and synthesized data. For the purposes of this study, the model space $m_{r s}$ is populated with the 
statistical parameters necessary to generate a reservoir realization,

$$
\mathbf{m}=\left[\begin{array}{ccccc}
m_{1,1} & m_{2,1} & \cdots & m_{R-1,1} & m_{R, 1} \\
m_{1,2} & m_{2,2} & \cdots & m_{R-1,2} & m_{R, 2} \\
\vdots & \vdots & \ddots & \vdots & \vdots \\
m_{1, S-1} & m_{2, S-1} & \cdots & m_{R-1, S-1} & m_{R, S} \\
m_{1, S} & m_{2, S} & \cdots & m_{R-1, S} & m_{R, S}
\end{array}\right]
$$

modified from Sen and Stoffa (1991), where each row (1 through $S$ ) corresponds to a particular statistical parameter and each column (1 through $R$ ) corresponds to a possible value that the respective parameter can attain. For instance, $m_{1 \rightarrow R, 1}$ may correspond to $R$ possible values for mean channel widths, $m_{1 \rightarrow R, 2}$ may correspond to the $R$ possible standard deviations associated with the mean channel widths, etc.

An initial model $m_{1,1 \rightarrow S}$ is selected and used to parameterize the generation of a realization in the same fashion as stated above. Subsequent to forward modeling, which is discussed in a later section, an energy function $E$ is evaluated via a normalized cross-correlation between each synthesized $u_{s}$ and observed $u_{o}$ seismic traces. When this comparision is performed in the Fourier domain, two solutions for the cross-correlation can be applied. Equation 2 will render a perfect correlation when the absolute amplitudes and travel time of the data match the synthetics

$$
E\left(m_{r s}\right)=\frac{2\left(u_{o} u_{s}^{*}\right)}{u_{o} u_{o}^{*}+u_{s} u_{s}^{*}}
$$

whereas equation 3

$$
E\left(m_{r s}\right)=\frac{\left(u_{o} u_{s}^{*}\right)}{\left(u_{o} u_{o}^{*}\right)^{1 / 2}\left(u_{s} u_{s}^{*}\right)^{1 / 2}}
$$

will ingnore absolute amplitudes and concider only relative amplitudes and travel time of the events (Sen and Stoffa, 1991). The model attains the mean energy value for all $u_{s}$ and $u_{o}$ 
pairs. This process repeats for all $R$ values of the current parameter maintaining constant values for $m_{1,2 \rightarrow S}$. A probability distribution $P$

$$
P\left(m_{r s}\right)=\frac{\exp \left(\frac{-E\left(m_{r s}\right)}{T}\right)}{\sum_{r=1}^{R} \exp \left(\frac{-E\left(m_{r s}\right.}{T}\right)} \text { where } T=T_{0} * 0.99^{i}
$$

is evaluated, which calculates the likelihood that any one of the $R$ values of the current parameter is correct based on the energy function $E$.

A new value for the current parameter is retained based on this probability distribution and the process continues to the next parameter maintaining constant values for parameters $m_{r, 1}$ and $m_{1,3 \rightarrow S}$. An iteration $i$ in the annealing process constitutes the completion of evaluating the $R^{\text {th }}$ value of the $S^{\text {th }}$ parameter, the temperature $T$ is lowered, and the cycle repeats until an acceptable match between the observed and synthesized data is attained. To establish a computationally efficient cooling process, experimental trials are often performed before selecting the initial temperature $T_{0}$.

For the purposes of this study, fourier synthesis of seismic data provides a computationally efficient means of generating synthetic seismic data. A convolution model has been adopted to generate the synthetic post-stack seismic data. Each realization is converted to an impedance volume based solely on the occurrence of the architectural objects and associated impedance values. The synthetic seismic data results from the convolution of the reflectivity series with a $32 \mathrm{~Hz}$ Ricker wavelet. When this operation is performed in the Fourier domain, it simplifies to a mere multiplication. Since the necessary calculations during the inversion process (i.e. energy function) can be performed in the Fourier domain, the synthesized seismic data need not be transformed back to the time domain.

\section{Coalinga heavy oil field}

Our method of generating reservoir realizations is applied to Chevron's Coalinga heavy oil field in southwestern California. The Coalinga field is a mature field with an abundance 
of core and wireline log data. The relative abundance of geologic and petrophysical data makes this a suitable reservoir to assess the results of our realizations since wells can be excluded to be used for control.

\section{Temblor formation}

The Coalinga field has been oil and gas productive from the Temblor formation since the early 1900's. This unconformity-bounded reservoir can be subdivided into three main depositional zones as shown on Figure 1. The basal zone is bounded at the base by a major erosional surface, Base Temblor, and at the top by the Buttonbed unconformity. This Buttonbed unconformity marks the transition to tide and wave dominated shoreline facies, which is in turn capped by the Valv unconformity. This unconformity defines the transition

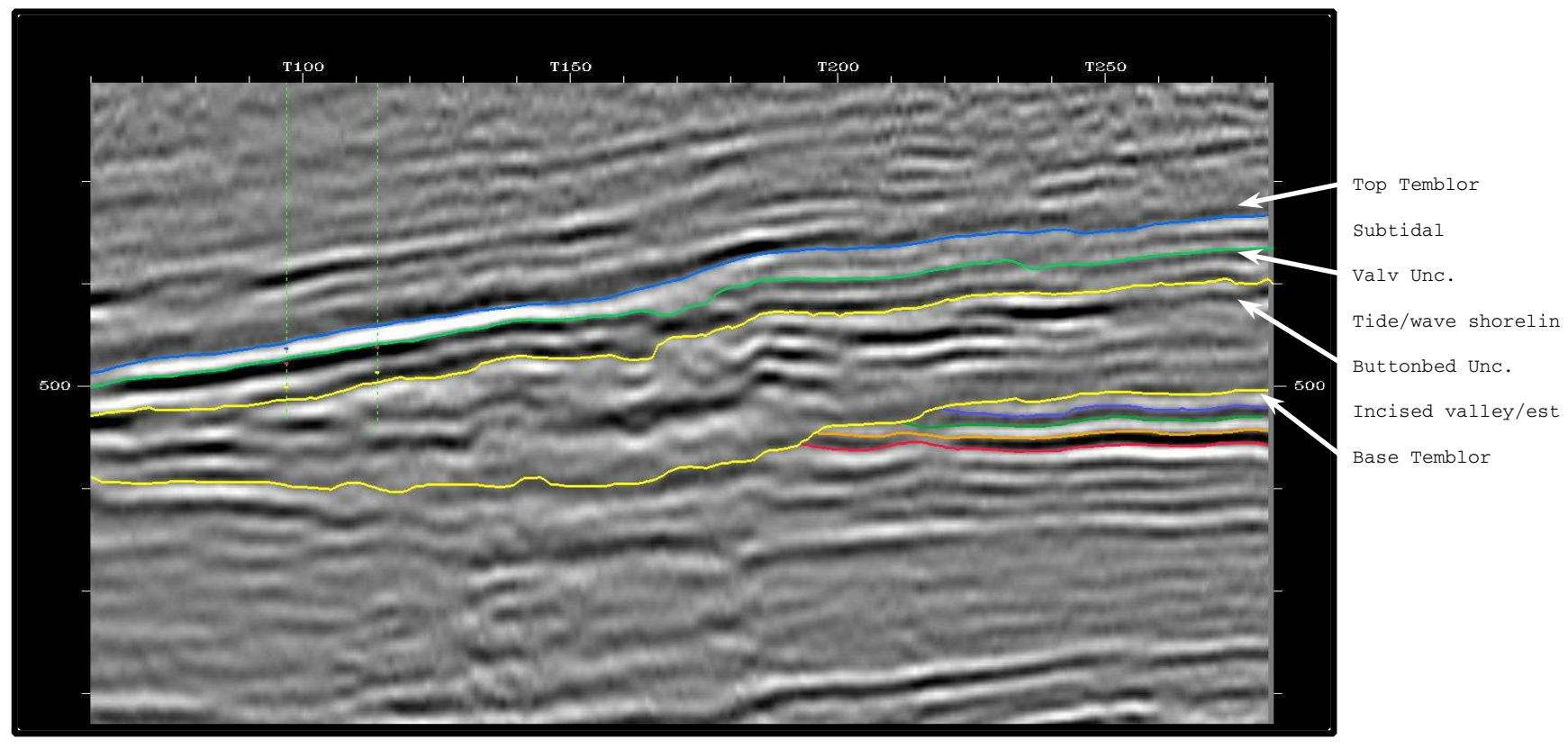

Figure 1: The dominant facies zones within the Temblor formation

Currently, production is focused in the basal zone of the Temblor formation and is aided by steam injection. Bridges and Castle (2002), describes two dominate facies types within this basal zone, incised valley facies overlain by estuarine facies. Incised valley facies types 
were characterized by stacked channel deposits associated with incisions exhibiting high topographic relief. A general fining upward succession of sediment from the fluvial channel deposits to estuarine channel deposition conforms to a relative sea level rise during the Miocene.

\section{Preliminary experiments}

The object-based stochastic facies inversion was initially performed on the basal zone of the Temblor formation. Rectangular prisms were used to model the seven facies types observed in the core logs. These facies types included sand, burrowed clay, burrowed sand, fossiliferous sand and clay, laminated silt sand and clay, limestone, and calcareous cemented sand. The mean widths of these objects were varied from 4 to 45 feet, lengths ranged from 60 to 675 feet, thickness from 30 to 337 feet, and the orientations were allowed to vary from $9^{\circ}$ to $100^{\circ}$. The standard deviations associated with the aspect ratio and orientation was set to 0.20 the mean value. The average impedance values, as determined from the core and wireline log data, with a range of \pm 0.20 the average values were assigned to the facies types.

The results of this preliminary experiment, shown in 2 , perfectly matched the core data and achieved a 0.20 scaled cross correlation with the recorded seismic data over this basal zone.

\section{Conclusion}

The adaptation to conventional techniques of generating reservoir realizations manifests itself by utilizing a waveform inversion technique as a proxy to geologic intuition and analogs. The recovery of the parameters that define the composition and internal structure of a reservoir through this formulation will aid in resolving inter-well and possibly inter-trace heterogeneity. 


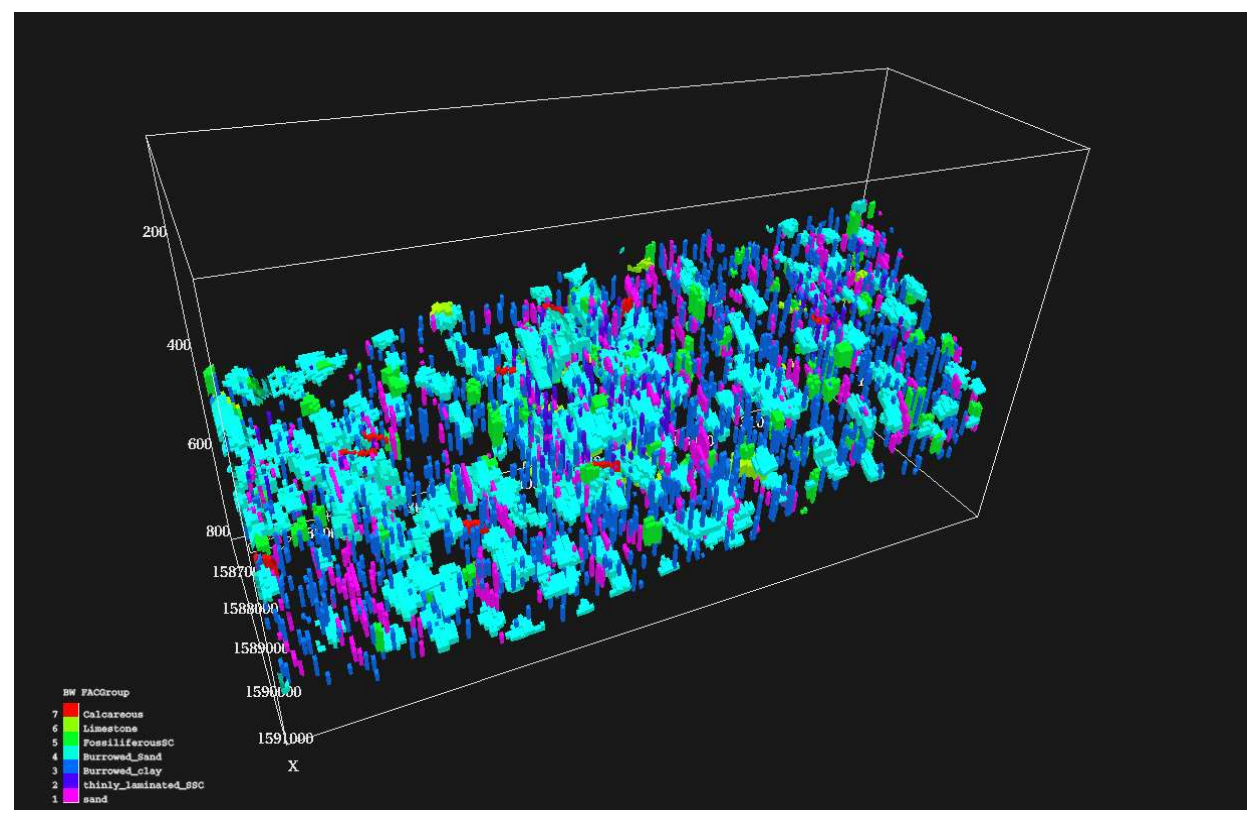

Figure 2: The results of the preliminary experiments performed on the basal zone of the Temblor formation.

\section{References}

Robert A. Bridges and James W. Castle. Local and regional tectonic control on sedimentology and stratigraphy in a strike-slip basin: Miocene temblor formation of the coalinga area, california, u.s.a. Masters Thesis, 2002.

M. K. Sen and P. L. Stoffa. Nonlinear one-dimensional waveform inversion using simulated annealing. Geophysics, 56:1624-1638, 1991. 


\title{
Deterministic High-Resolution Seismic Reservoir Characterization
}

\author{
Sailendra N. Mahapatra and Matthias G. Imhof
}

\section{Introduction}

Reservoir characterization and model building are necessary steps to develop an oil field. Reservoir Characterization is the three-dimensional delineation of a reservoir, its structural framework, volume, heterogeneity, and distributions of rock and fluid properties, which allows maximizing production and minimizing costs, for example by optimizing well locations. Reservoir models are necessary to evaluate risks and production scenarios. These models depend on fluid content, composition, and structure of the reservoir.

The conventional approach to seismic reservoir characterization involves integration of geologic and seismic data. The reservoir model is based on lithological parameters estimated from well cuttings, core, and wireline logs. The interwell gaps are interpolated by either by geologic concepts or geostatistics. In either case, the final models of key petrophysical parameters are inconclusive and may differ from the real reservoir. The conventional seismic resolution limit of one-fourth of the seismic wavelength may not permit perfect estimation of the reservoir heterogeneities, in the absence of a well-defined geological depositional structure.

The objective of this investigation is to integrate seismic data, well data and geologic concepts into lithological and petrophysical models with geologic and stratigraphic constraints, internal consistency, and compatibility with seismic data and wireline logs.

We will first demarcate and delineate the reservoir into seismostratigraphic and seismogeomorphic elements bounded by unconformities and depositional geobodies. For each element, we will convert seismic attributes into porosity model by using a neural network.

We will use industry standard software such as the Landmarks' suites, VoxelGeo and Hampson-Russel. This is the third year of this research investigation.

\section{$\underline{\text { Seismo-stratigraphic Interpretation }}$}

We correlated wireline logs and identified the four unconformable surfaces based onto the shale base line shifting values (Fig. 2,3). The time equivalents of these unconformities were posted to the poststack 3D seismic data. While trying to map these surfaces on the seismic data, we observed severe misties and reflector discontinuities on the seismic sections, because the 3D data set was actually merged from different surveys acquired at different times in an area with multiple steam injection activities. Line tying unconformity reflectors is problematic. Reverting to reprocessing the data was deemed too time consuming and beyond the scope of the present investigation. Instead, we developed novel technique to aid the interpretation. We map a deeper, relatively continuous reflector and flatten it. The misties in the overburden are reduced considerably on this flattened volume and the continuity of these unconformities is improved. The flattened volume with time shifted wireline data allows interpretation of the unconformities in the original discontinuous seismic volume.

The strike of the Temblor formation is NNE-SSE. The 2-way time thickness of Temblor formation is about 240-260 ms (130-150, 30-40, 35-40 ms respectively from bottom most unconformity). In seismic data, offlap, reflector truncation, and onlap are observed against the unconformities (Fig. 4, 5) which 
allow their identification as sequence boundaries. As observed in the depth map, the highest structural relief is observed towards West. The zone between Button and Basal Temblor contains a multitude of channel cuts (Fig. 5). In the lower central part of the study area, these channels appear to be re-cut and restacked which is more prominently observed in the dip direction (Fig. 5). The depositional direction seems to be changing over the field for different geologic time of deposition (NW to SW). There is a reflector mismatch when following reflectors from the north or the south, respectively. The reason may be statics or data merge. In the Western part, the Buttonbed and Valv surfaces appear to be merging which signifies that portion of Button has been eroded by the overlying Valv unconformity (Fig. 1).

\section{$\underline{\text { Seismo-geomorphic Interpretation }}$}

\section{Geovolume Visualization and Interpretation}

Within the past few years, advanced computing power enable us to stretch the resolution limit to the maximum possible with the help of the new technology 'Geovolume Visualization and Interpretation (GVI)'. Correct and appropriate selection of any attributes (hybrid or multiple attribute system) along with these visualization techniques may help to analyze a particular geological situation more effectively and may help in field delineation. These techniques help us to demarcate and delineate the reservoir into sub-units, based on its depositional signatures and geological characteristics. The technology and philosophy of GVI differs dramatically from conventional line-based interpretation and includes new interpretation strategies and methodologies. It allows 3-D seismic interpreters to rapidly analyze enormous data volumes by tapping the mind's eye and by incorporating seismic attributes into interpretations much earlier in the interpretation process. The process starts with volume visualization followed by volume interpretation. Volume visualization is a method of seismic interpretation in which the geophysicist directly evaluates the seismic reflectivity of the subsurface in 3D space by applying various levels of transparency to the data. Volume interpretation provides a method for geoscientists to quickly evaluate complex structural, stratigraphic, and amplitude features in 3D space. Kidd (1999) categorizes two basic types of visualization:

- Map-based (surface visualization)

- Volume-based (volume visualization)

Surface visualization results from mapping individual horizons and faults, and then re-interpreting them collectively in 3D space as a 3D model. It is the logical end product of conventional mapping processes after surface mapping. Its interpretation assumes that the seismic reflectivity of the subsurface is an "in situ" 3D model of the subsurface, which, by its nature, consists of integrated structural, stratigraphic, and amplitude features in 3D space.

The four main techniques of GVI are recognition, color, motion, and isolation (Sheffield, et al., 2000). Recognition helps in distinguishing characteristics of an event to be mapped. This is followed by further processing to enhance those recognized characteristics for visualization and geobody mapping (Meyer, et al., 2001). Using an appropriate color scheme, the resultant color attribute is a direct representation of the seismic attribute distribution (Kidd, 1999). Depth cueing, lighting, and intensity are some of the important components associated with the color viewing. Motion provides the ability to move an object in a manner continuous to the human eye simultaneous with control movements. It allows observation how the data is related in space and time. Isolation, the ability to separate events of interest from other data, is another key feature of GVI. This is achieved by rendering the opacity values for the extraneous attribute amplitude values and creating a relatively transparency scheme for marginally important amplitudes. It helps in illuminating stratigraphic and geomorphic architecture within the reservoir (Harvey et al., 2000).

Various instantaneous attributes are used for the visualization. Figure 6 shows the seismic architectural setting over the entire area of our study. Figure 7 shows a channel geometry pattern as observed in both inline and cross-line at the same location. The stratification pattern of the reservoir is observed in Figure 
8. Absolute instantaneous acoustic amplitude slices in different directions in the reservoir depict the overall beds disposition pattern. Looking at a NE-view of the reservoir, we observe that there are two prominent channel systems (major one in top and another in bottom part of the reservoir) (Fig. 9 and 10). The one in top part is gradually shifting towards ESE-SE; the bottom channel system appears to be shifting SSE. Figures 11 and 12 show cubes showing the distribution pattern of these channel systems based on their reflection strength (absolute amplitude envelope). Figure 13 shows the opacity editor which shows the chosen transparency scheme and amplitudes for display in the above two volumes. It is interesting to note that these attribute volumes clearly depict two distinctive distributions of reservoir rocks over the field. The yellow bodies may be the clastic reservoir sands that we are looking for. The lithology type is further evident by the presence of hydrocarbon (red, highest amplitude) in those yellow bodies and our knowledge that the reservoir rock is sands. It is planned to further delineate these groups in both time and in space.

Careful GVI will help in segmenting the area of study as channel and non-channel bearing volumes. Further, the volume may be subdivided into sub-units based on the position of the three unconformities in the Temblor formation.

\section{Future Works}

The integration of geological features with the 3D seismic data will be continued. The relationship between seismic attributes and various reservoir litho-types will be ascertained with the help of reservoir attribute visualization and extrapolation analysis. The generated cross-plots of seismic attributes and wellderived parameters and their correlation matrix will provide an integrated analysis environment for discovering subtle or hidden relationships between reservoir properties and seismic derived attributes. Reservoir properties and extents may be accurately predicted away from well control. Further, the study will be focused to determine the most-appropriate seismic attribute amplitude ranges corresponding to various reservoir lithologies (based on correlation of cores/wireline log parameters with seismic attributes) for rendering the appropriate isolation of extraneous amplitudes, which will be used for GVI and voxbody sculpting and interpretation.

The reservoir model based on our integrated characterization based on volume segmentation by geobody visualization and interpretation will substantially reduce the cost of hydrocarbons exploitation in the geologically complex, heterogeneous, stratigraphic plays of Coalinga field. This cost reduction would be observed through improved injection and extraction well planning resulting from reservoir models that more closely mimic the petrophysics of the producing reservoir. Furthermore, model will serve as a benchmark for subsequent production and field development activities.

\section{References}

Bate, Matthew, Adam, 1984, Temblor and Big Blue formations: interpretation of depositional environment sequence on Coalinga anticline, Fresno County, California, Masters Thesis, Stanford University.

Bridges, Robert, A., and Castle, James, W., 2002, Local and regional tectonic control on sedimentology and stratigraphy in a strike-slip basin: Miocene Temblor formation of the Coalinga area, California, U.S.A., Masters Thesis, Clemson University.

Bridges, Robert, A., and Castle, James, W., 2003, Local and regional tectonic control on sedimentology and stratigraphy in a strike-slip basin: Miocene Temblor formation of the Coalinga area, California, U.S.A., Sedimentary Geology, 158, pp. 271-297.

Brown, A. R., 1996, Interpretation of Three-Dimensional Seismic Data Tulsa, The American Association of Petroleum Geologists Memoir 42. 
Bulloch, E. Terra, et al, 2001, Examination of a turbidite system using 3-D visualization and multiple seismic attributes, Albacora Field, deepwater brazil, expanded abstract, ann. Internat. Mtg., SEG, Texas.

Clark, M. S., Tucker, K. E., and Klonsky, L. F., 2001, Geological study and multiple 3D surveys give clues to complex reservoir architecture of giant Coalinga oil field, San Joaquin Valley, California, The Leading Edge, 20, p. 744-751.

Coffeen, J. A., 1990, Seismic on screen, an introduction to interactive interpretation, PennWell, OK

Harvey, E.A.L., et al, 2000, Techniques for volume interpretation of seismic attributes, $68^{\text {th }}$ Ann. Internat. Mtg. Expanded abstract, SEG Calgary.

Kidd, D. Gerald, 1999, Fundamentals of 3_D seismic volume visualization, The Leading Edge, 18, pp. $702-712$.

Marfurt, Kurt, J., Kirlin, R., Lynn, Farmer, Steven, L., and Bahorich, Michael, S., 1998, 3-D seismic attributes using a semblance-based coherency algorithm, Geophysics, 63, pp. 1150-1165.

Miall, A. D. and Arush, M., 2001, Cryptic sequence boundaries in braided fluvial successions, Sedimentology, v. 48(5).

Meyer, E. Douglas, Harvey, L. Elizabeth, et al., 2001, Use of seismic attributes in 3-D geovolume interpretation, The Leading Edge, Issue 12, p. 1377-1380, 1400.

Posamentier, H.W. and Vail, P.R., 1988, Eustatic controls on clastic deposition II - Sequence and system tract models. In: Sea-level Changes: an Integrated Approach, Ed. By C.K. Wilgus, et al.), Spec. Publ. Soc. Econ. Paleont. Miner., 42, p. 125-154.

Sheffield, M., Tatum, et al, 2000, Geovolume visualization interpretation: A lexicon of basic techniques, The Leading Edge, 19, Issue 5, p. 518-522.

Shanley, K. W. and McCabe, P. J., 1994, Perspectives on the Sequence Stratigraphy of Continental Strata, AAPG Bulletin, v. 78, No. 4.

Shuki, R., et al., 1994, Seismic-guided estimation of log properties, Part 2, The Leading Edge, June, pp. 674-678.

Taner, M. T. Koehler, F., and Sheriff, R., E., 1979, Complex seismic trace analysis, Geophysics,. 44, pp. 1041-1063

Yilmaz, Ozdogan, 1987, Seismic data processing, Society of Exploration Geophysicists, Tulsa, OK.

Van Wagoner, J.C., Posamentier, H.W., Mitchum, R. M., et al., 1988, An overview of the fundamentals of sequence stratigraphy and key definitions, in Wilgus, C.K., et al., eds., Sea level changes: an integrated approach: SEPM Special Publication 42, p. 39-45.

Walls, D. Joel, et al, 2002, Seismic reservoir characterization of a U.S. Midcontinent fluvial system using rock physics, poststack seismic attributes, and neural networks, The leading Edge, 21, pp. 428437. 


\section{$\underline{\text { Appendix }}$}

\section{Figures}

Line 110
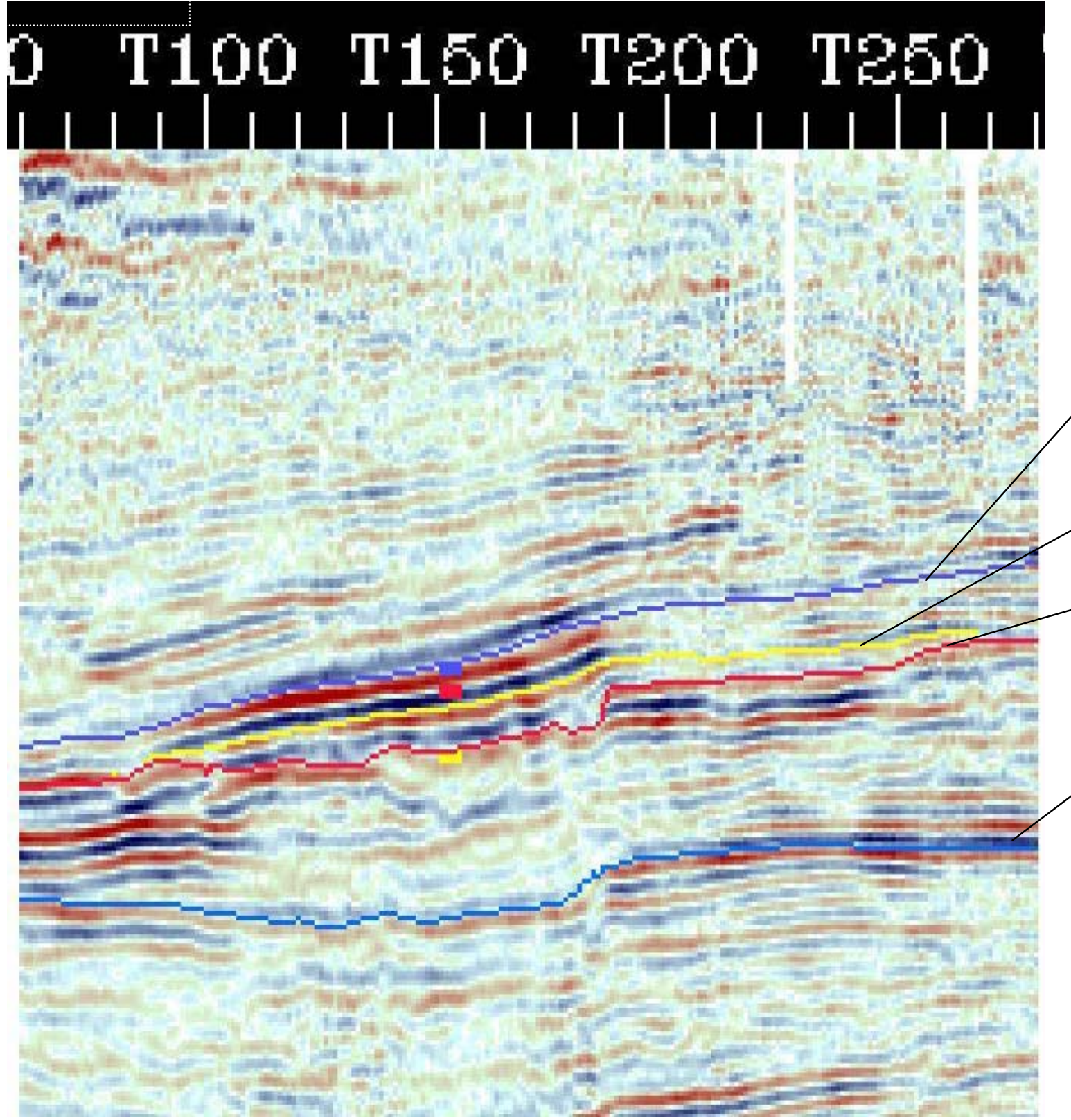

Top Temblor unconformities

ZONE C

Valv unconf. ZONE B

Buttonbed unconf.

ZONE A

Base Temblor Unconf.

Figure 1. Unconformities within the Temblor sequences 


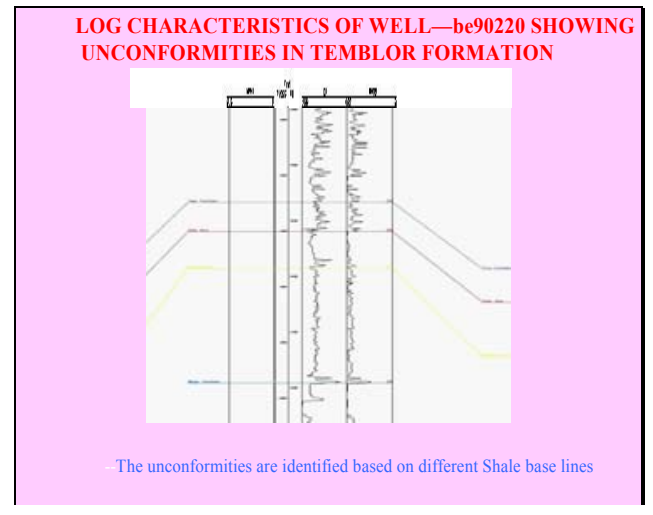

Figure 2. Log characteristics of a Coalinga well

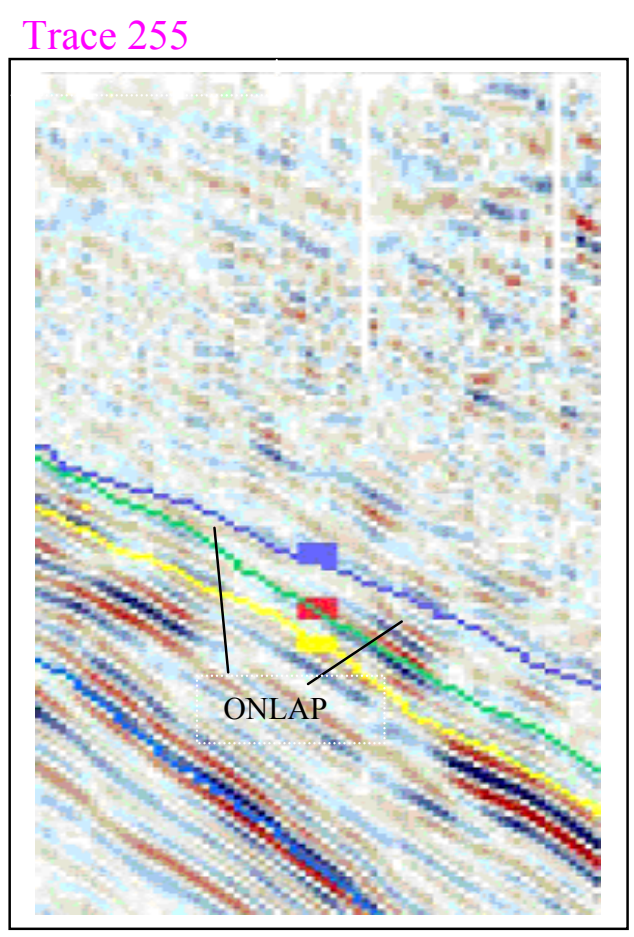

Figure 4. Shows onlap of reflector. The yellow and green colors represent Buttonbed and Valv unconformity respectively.

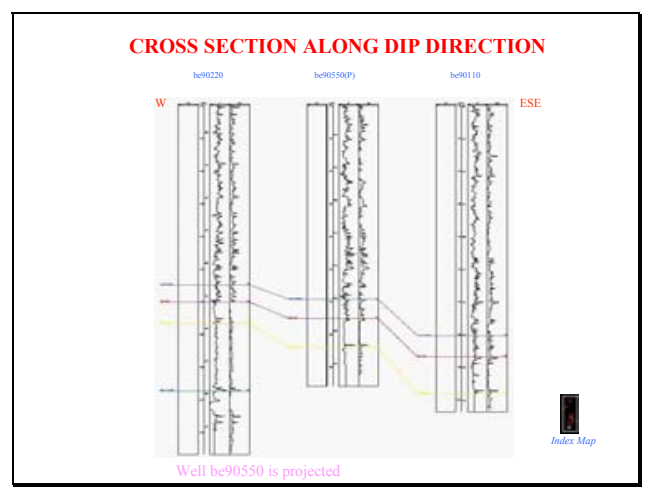

Figure 3. Log correlation along dip direction of Coalinga Field

Trace 150

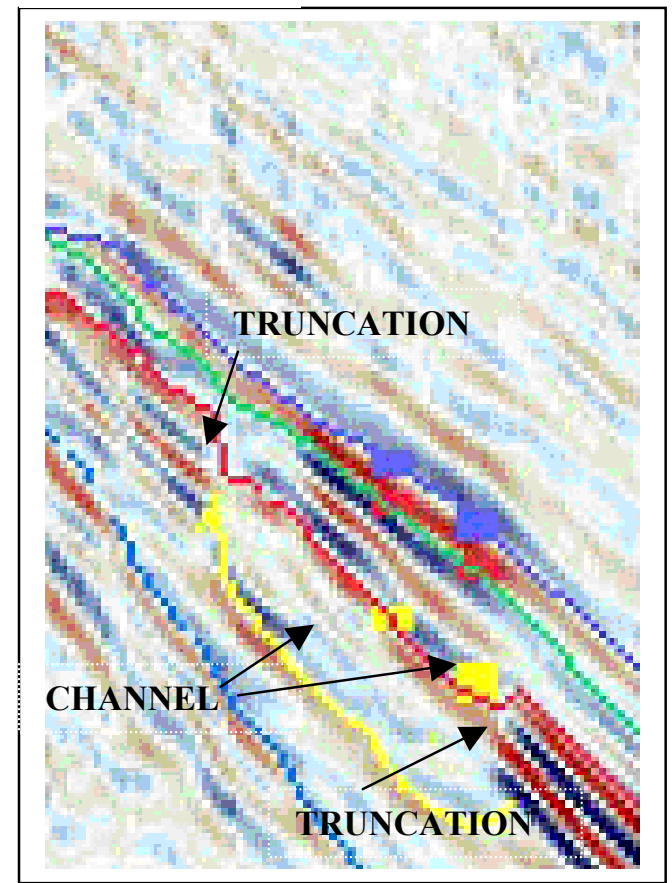

Figure 5. Shows truncation of reflectors, and channel in between Buttonbed (red) and Basal (Blue) unconformities. Channel is also seen within the Buttonbed-Valv (green) unconformities. 

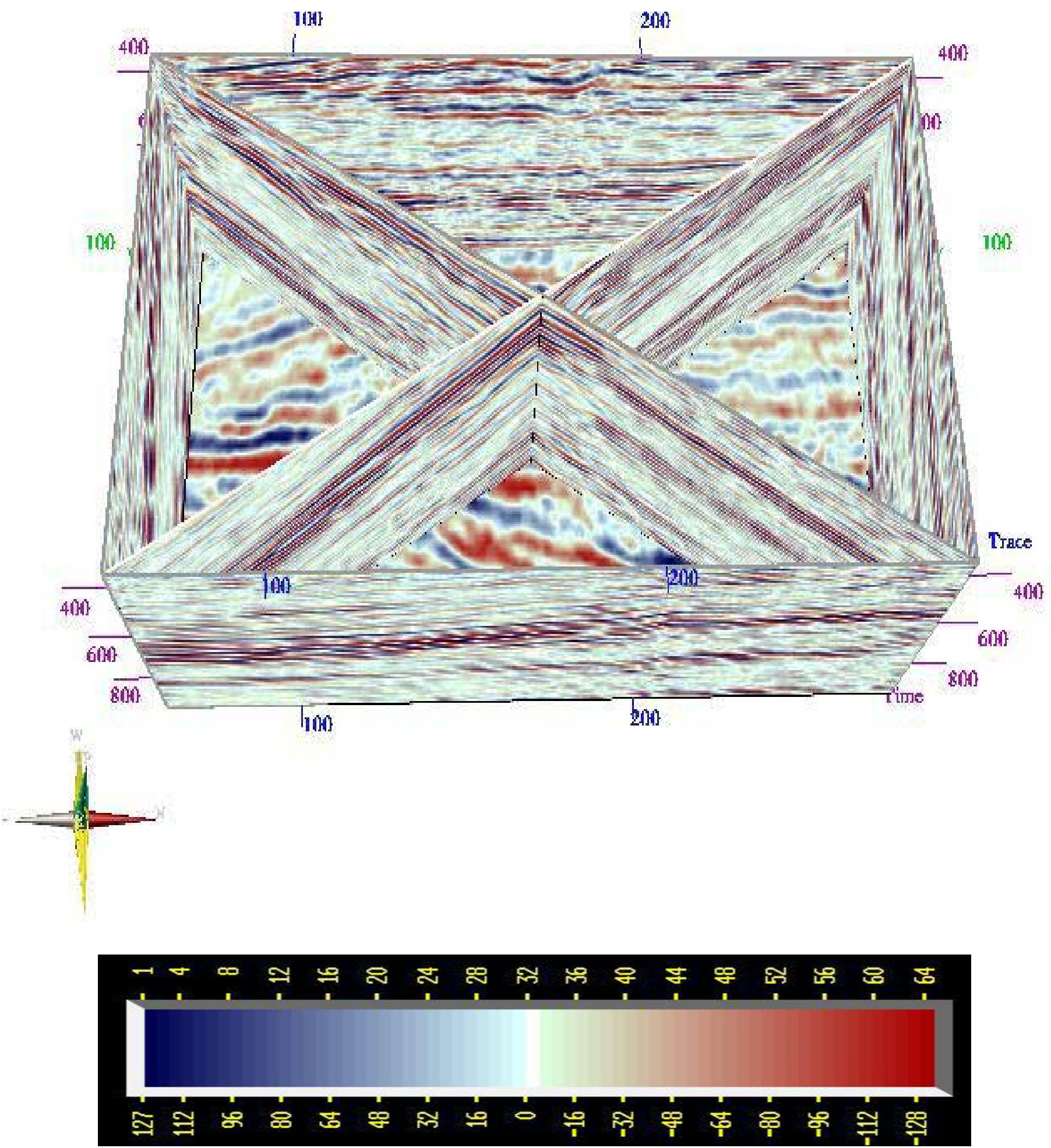

Figure 6. Seismic architectural display in colors for Temblor Formation. 


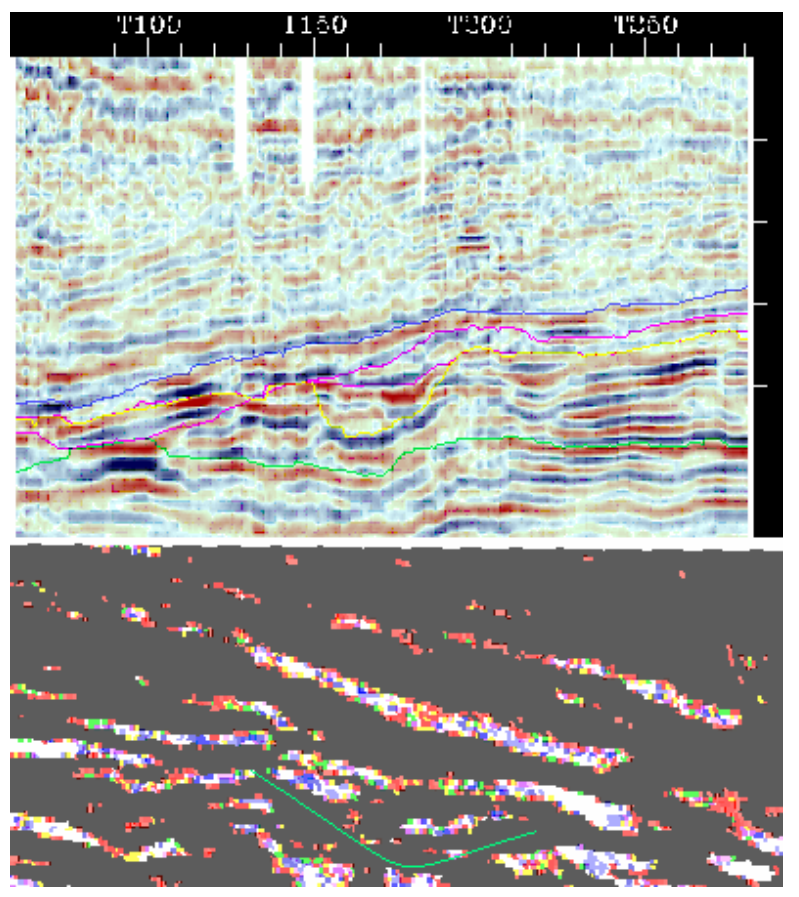

Figure 7. Channel seen on Line 81. The bottom picture shows the same channel in voxel bodies in Trace 171 .

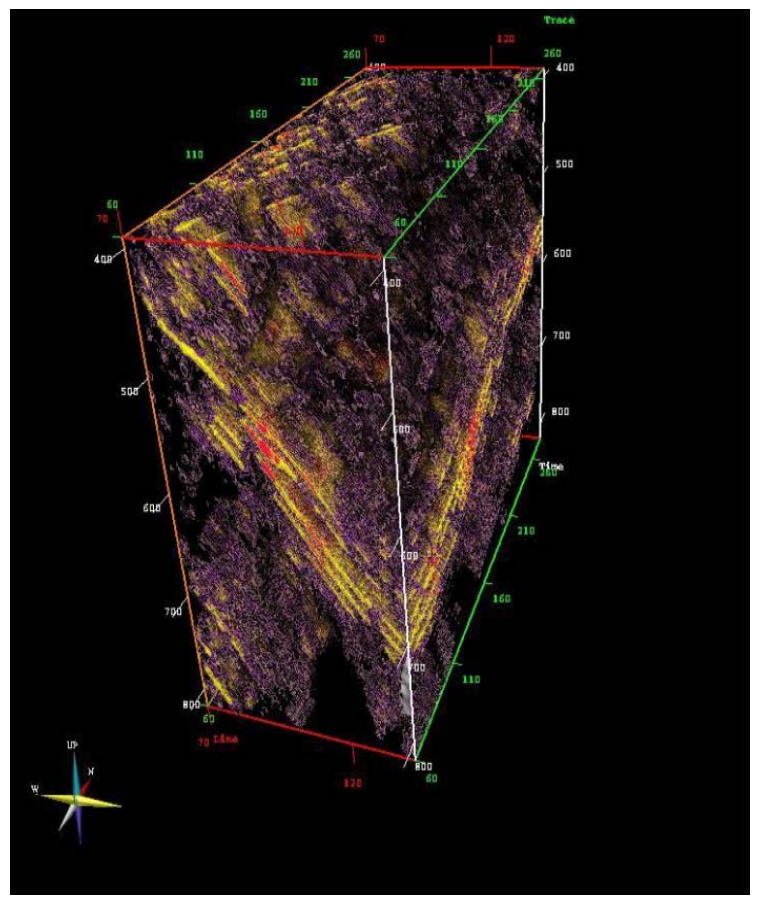

Figure 8. Cube of absolute amplitude showing pattern of stratification.

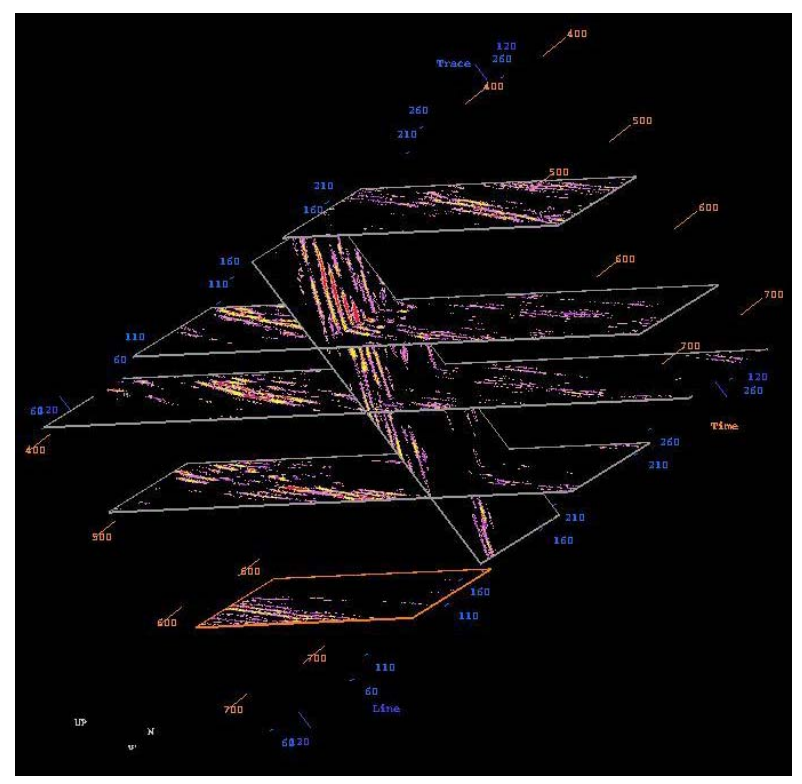

Figure 9. Absolute amplitude slices showing beds disposition.

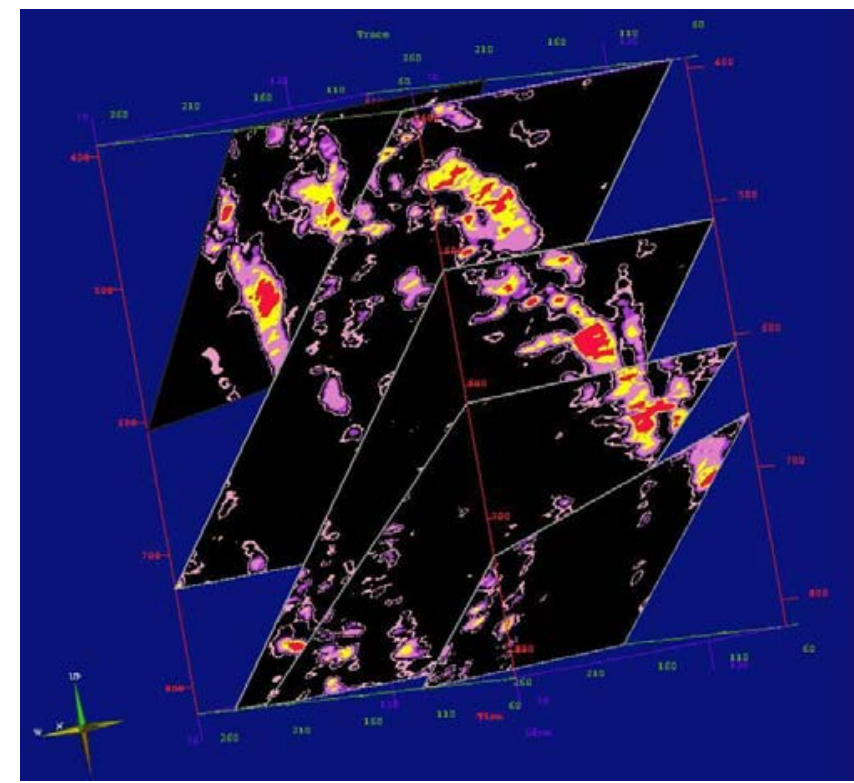

Figure 10. Oblique slices of reflection strength attribute. Note channels (yellow) course shifting towards ESE-SE. A second channel is also seen towards west shifting towards SSE (left, upper part). The high amplitudes (red) are probably hydrocarbon. 


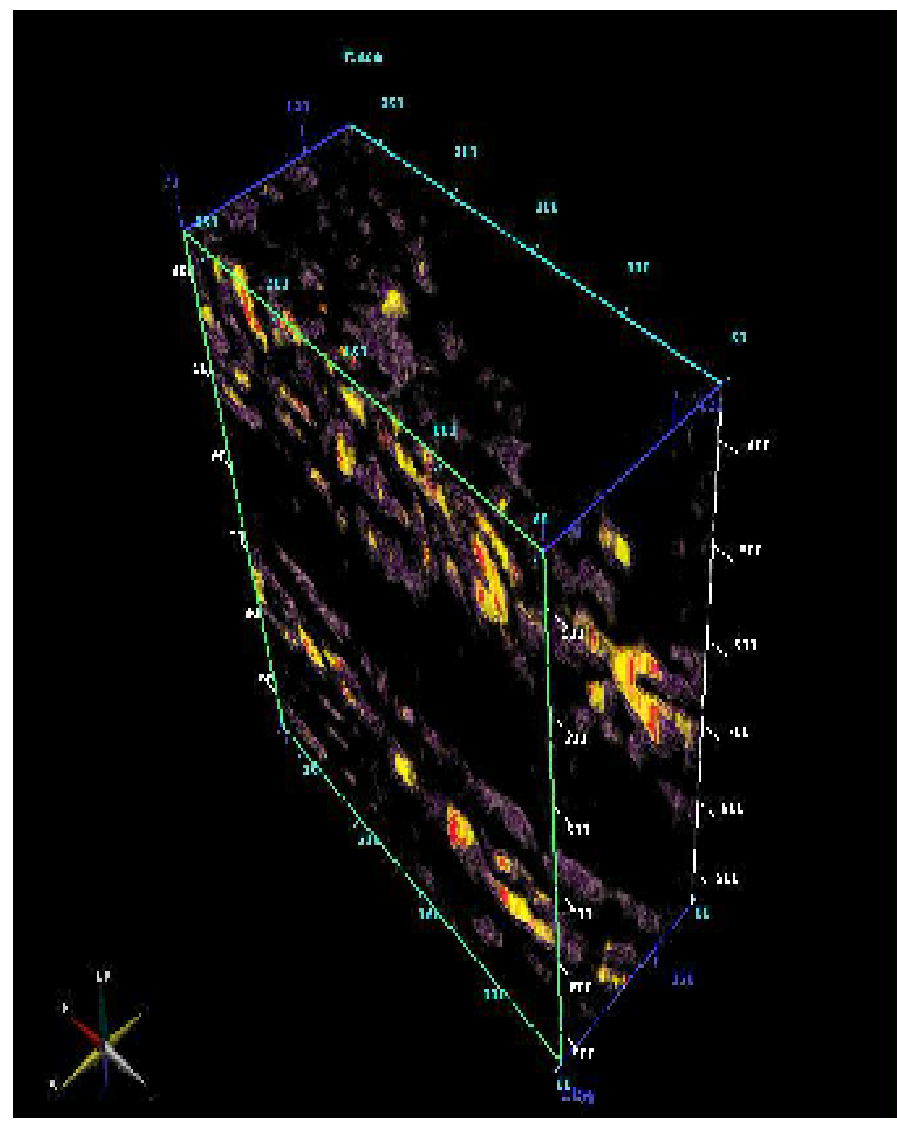

Figure 11. Reflection strength attribute cube showing channel bodies (yellow) distribution. The high amplitudes (red) is probably hydrocarbon.

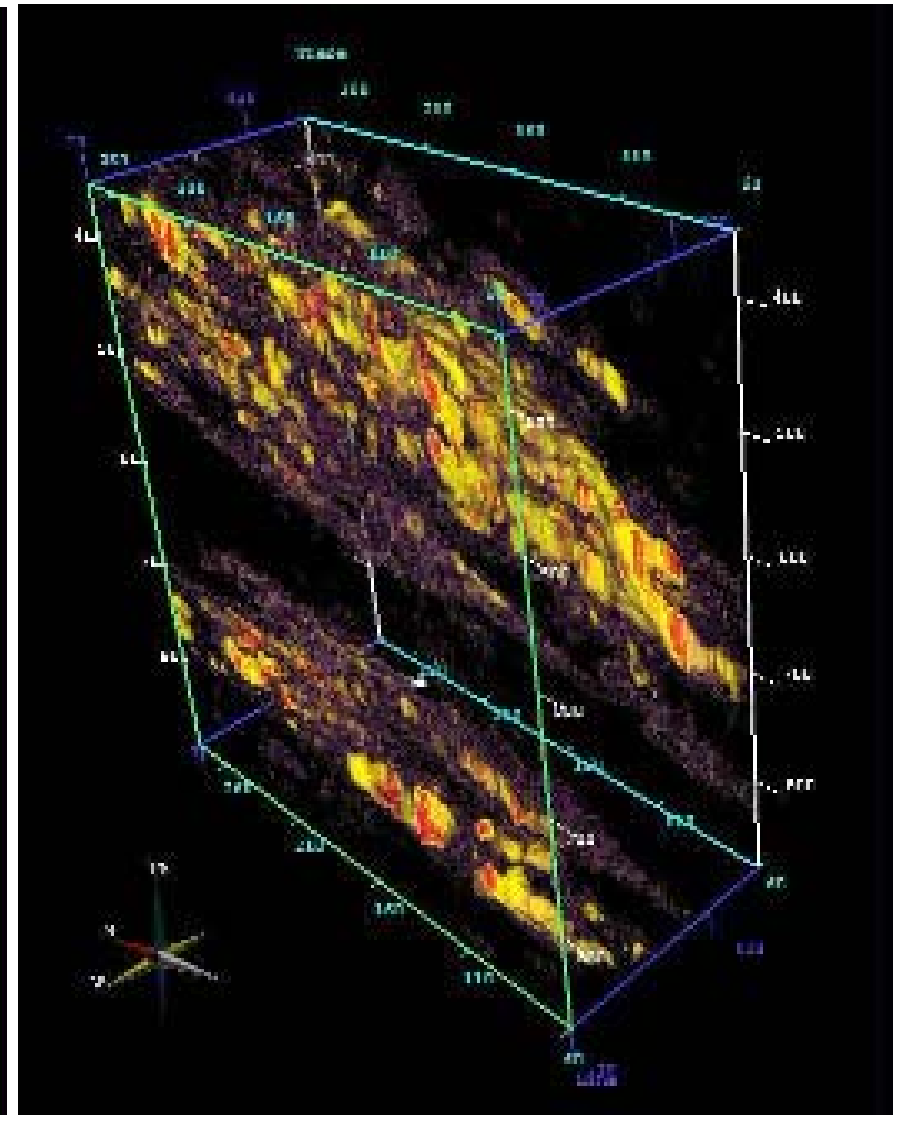

Figure 12. Reflection strength attribute cube showing sand bodies (yellow) distribution. The high amplitudes (red) are probably hydrocarbon. Note the absence of any prominent porous reservoir rocks between 550-700 ms from NW.

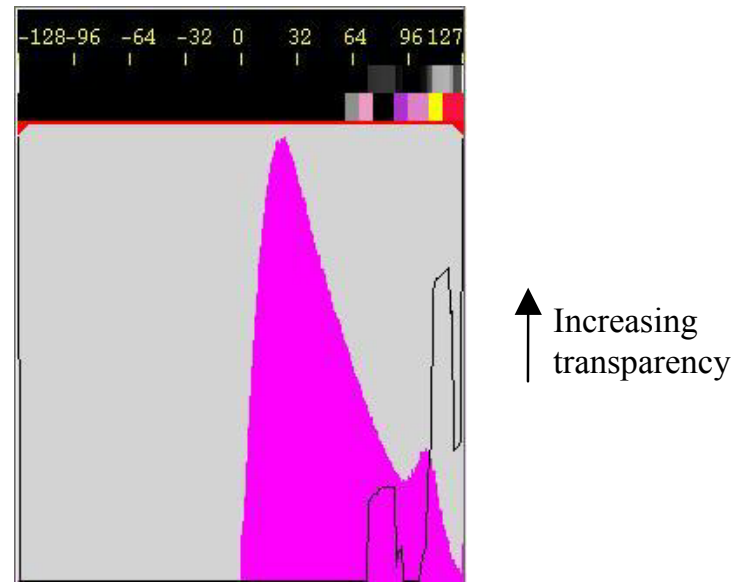

Figure 13 Opacity editor showing the histogram of absolute amplitudes (pink), and the chosen transparency level (curve in black inside the histogram) for different amplitude values (top of the figure) for obtaining the figures 11 and 12). 


\title{
Integration of Geologic Models and Seismic Data to Characterize Interwell Heterogeneity of The Miocene Temblor Formation, Coalinga, California
}

\author{
Jaime Piver and James Castle
}

Three data sets were used in this study including: lithofacies data from core and outcrop studies, geophysical log data, and 3D seismic data. Core and outcrop studies were completed by prior researchers at Clemson University (Bridges, 2001; Mize, 2002). The results from these investigations were used in determining bounding surfaces and lithofacies groups used throughout the current study.

Well data from 198 wells in study area 1 and 71 wells from study area 2 were utilized throughout this investigation. Sonic, density, gamma-ray, and scaled gamma-ray logs were used to identify bounding surfaces and lithofacies, create geologic models and to aid in the analysis of the seismic data.

Geologic models were created for this project using IRAP reservoir modeling software (RMS) version 7.0. IRAP RMS has the capability of integrating multiple data sets including seismic data cubes. Three types of models were created for this project: stochastic lithofacies, stochastic composite, and deterministic. Stochastic models use geostatistical analysis to interpolate interwell heterogeneity. While deterministic models distribute information from gamma-ray and density logs throughout the models providing a representation of lithologic and density variations within the formation that may impact seismic wave propagation.

An extensive 3D-seismic data set was collected in 1996-2000 to provide seismic coverage of West Coalinga Field (Clark et al., 2001). The data were processed at Virginia Tech and Seismic Micro-Technologies; The KINGDOM Suite+ software package was used to analyze the seismic data. SMT is a comprehensive seismic interpretation program that allows for the selection of bounding surfaces directly on seismic traces and the 
seismic data can be exported from SMT as SEG-Y files into IRAP RMS as continuous parameters used to create conditioned models.

\section{Procedures}

Nineteen procedures were used to complete this study:

1. Formatting of geophysical logs;

2. Depth to time conversion of log data;

3. Selection of bounding surfaces and lithofacies groups from geologic information (cores, outcrops, and well logs);

4. Loading seismic data into SMT;

5. Generation of synthetic seismograms;

6. Selection of seismic horizons;

7. Confirmation of seismic horizons selection through the generation of seismic structure maps;

8. Generation of seismic attributes in SMT;

9. Determination of lithofacies body shapes;

10. Loading, generating, and checking well data, bounding surfaces, and seismic attribute data into IRAP RMS;

11. Defining modeling grids;

12. Generation of lithofacies and deterministic models;

13. Analysis of model results from lithofacies and deterministic modeling;

14. Re-sampling of seismic attribute data;

15. Generation of facies probability density functions;

16. Generation of composite models conditioned to re-sampled attribute data;

17. Analyze composite modeling results

18. Determination of the data set or combination of data sets that best improves the resolution of interwell heterogeneities;

19. Determination of the modeling method that is most beneficial in characterizing steam flooded heavy oil sands.

\section{Equiprobable Realizations}

Deterministic models are created using continuous well data that results in a single outcome for each realization. Stochastic realizations have the ability to elaborate 
problems of missing data not with a single answer but with a suite of equiprobable models or models that fit the data equally well, this makes stochastic modeling a useful tool for multiple scenario analysis. These models provide a greater variety of results than the smooth deterministic models.

The equiprobable realizations that come from stochastic modeling commonly have a realistic texture in regions that are missing data. Without accounting for this, the models become too simplistic displaying facies that are too smooth and continuous or that gently undulate from one well to the next rather than showing the interwell variations that may exist.

The heterogeneity modeled in this study described the spatial distribution of rock properties that affect fluid flow (porosity and permeability) represented by lithofacies groups. The extent and continuity of the lithofacies groups has the greatest impact on fluid movement within the Temblor Formation. Modeling these heterogeneities involved establishing the known heterogeneity from well logs, core and outcrop studies, conditioning to seismic attributes and using statistical algorithms to simulate the spatial distribution in interwell regions.

\section{Lithofacies Continuity}

The heterogeneity modeled in this study described the continuity of lithofacies groups within the Temblor Formation. This continuity includes the spatial distributions and the interactions between lithofacies groups. The resolution of the seismic data did not provide a means of identifying individual lithofacies; instead, it was used as a conditioning parameter to create stochastic models and to identify the location of bounding surfaces.

Core and outcrop studies and well logs provided a means of characterizing vertical features, and stochastic lithofacies models created from these data provided a realization that could be used to identify the distribution of wells at well locations. In areas with minimal well spacing these models even provided some continuity in interwell locations.

The stochastic composite models conditioned to seismic attributes provided representations that displayed realistic continuity of the lithofacies groups. Models conditioned to instantaneous amplitude provided the most geologically reasonable 
representations of lithofacies continuity because they contain high amounts of spatial variation that is independent of well spacing and well locations, and honors well control.

This was demonstrated through the creation of several models with varying amounts of well control. The resulting realizations displayed features in interwell regions based on the instantaneous amplitude data and corresponding facies probability functions, yet in areas where wells were present the well control was honored before the seismic data. This is important because the well control present inputted into the models does not rely on probability; therefore in most cases can be considered more realistic.

\section{Improved Resolution of Subsurface Heterogeneity}

Seismic resolution is measured in terms of seismic wavelength, which is the quotient of velocity and frequency. Seismic velocity increases with depth while frequency decreases with depth. The result is a wavelength that increases with depth making resolution poorer (Brown, 1999). For this reason seismic data cannot resolve small-scale reservoir heterogeneities that exist at depths. However, the statistical properties of the heterogeneities can be inferred statistically from the seismic data. This was done in this study through the creation of facies probability functions, which define the relationship between seismic attribute values and the probability of encountering a particular facies, at a particular location within the formation.

A major component of this study was the development of stochastic composite models that are conditioned to seismic attributes and display stratigraphic interpretations of interwell regions. Mize (2001) created conditioned models using trend modeling where source data was provided only at a reference point (i.e. well locations). By using stochastic composite models that are conditioned to seismic attributes, the entire distribution of facies is controlled ensuring that the probability for simulating lithofacies within a specific grid follows defined facies probability density functions. By creating composite models that use both well and seismic data a much more reasonable representation of the reservoir is achieved and it is possible to identify and characterize interwell heterogeneities.

\section{Comparisons}

Several comparisons were made throughout the course of this investigation. These including: a comparison between the raw seismic data and the conditioned models; a 
comparison between the resulting conditioned models and scaled gamma-ray logs; a comparison of the two study areas by studying the cores and model results to characterize geologic differences; a comparison of the advantages and disadvantages of the three data sets and a comparison of the different types of models created for this project; and a comparison between this study and previous work that integrated multiple data sets.

\section{Comparison between Seismic Data and Conditioned Models}

An attempt was made to compare the original seismic data cubes with the resulting conditioned models to check the structure of the bounding surfaces and to evaluate how the models utilized the seismic data. This comparison was complicated because of scale difference between the original seismic data cubes and the resulting models (Figure 1). The Temblor Formation represented by the seismic data is narrow, but changing the z-scale in IRAP RMS causes the data to become obscure and prevents an accurate comparison.

\section{Comparison between Conditioned Models and Well Logs}

A comparison was also made between the resulting conditioned models and scaled gamma-ray logs. In some areas these comparisons did not prove very useful because the seismic conditioning neglected some of the lithofacies bodies in the wells. An example is seen in figure 38, a large gamma spike at $410 \mathrm{~ms}$, should correspond to the calcareous cemented sand lithofacies. However, this lithofacies body is not present in the model because as discussed earlier the facies probability functions for calcareous cemented sand in the subtidal facies of study area 2 do not show up at any attribute values. This demonstrates the importance of utilizing all available information, which will be discussed further later.

\section{Comparison of the Two Study Areas}

A comparison was made between the two study areas to try to identify the effects steam flooding might have on model results. Core descriptions from wells in each study area were compared in order to identify geologic differences that exist between the study areas that would affect modeling. These cores were described by Mize (2002).

In study area 1, the core shows many stratigraphic differences as to what was seen in study area 2. For example, in both the subtidal facies tract and the tide- to wave dominated shoreline facies tract, a more complete distribution of calcareous cemented 
sand is seen in study area 2. In addition, the distribution of clay lenses/nodules and burrowed structures is different between the two study areas. In the estuarine facies tract, many of these same differences exist.

Since most of the variation between the study areas is subtle, they cannot be identified on the seismic traces again demonstrating the importance of including as much information as possible to characterize small-scale heterogeneities. It was recognized that the two cores do not characterize the entire model areas, but the descriptions do support the idea that geologic changes occur between the study areas. This scenario suggests that the differences in model results for the two study areas reflect changes in geology and are not the result of steam flooding projects that have occurred at West Coalinga Field.

\section{Comparison of Data Sets}

Three data sets were used throughout this study including; 3-D seismic data, lithofacies data from core and outcrop studies, and log data. A comparison was made between these data sets to characterize the types of information provided by each, their resolution, and their advantages and disadvantages. While each data set provides important information in characterizing a reservoir, a combination of all three data sets is necessary in characterizing the entire reservoir including small-scale heterogeneities.

Lithofacies data from core and outcrop studies provide the only means of identifying the true geologic features of the reservoir. Cores provide an excellent means of characterizing subsurface lithofacies, but coring every well in the reservoir is not economical and the lateral extent of the lithofacies bodies cannot be determined from cores alone.

Well logs are available for every well in the field. However, interpretation of lithofacies displayed on the logs relies on core and outcrop studies. Without them, the general interpretations can be made on the logs (i.e. identifying sand versus shale or limestone), but the small-scale heterogeneities cannot be characterized from well logs alone. In addition, the data collected from logs applies at well locations, and while it may be possible to interpolate facies between wells, some heterogeneity will be overlooked in interwell regions.

3D seismic data provides continuous and dense amounts of data across the field. However, small-scale heterogeneities cannot be identified with the current resolution of 
the data. Therefore, interpretation procedures rely on information gathered from well logs, cores, and outcrops to identify bounding surfaces and some of the interwell heterogeneity. For all of these reasons, the only way to characterize small-scale heterogeneities is to combine or integrate all three-data sets as was done in this study.

\section{Comparison of Model Types}

Three model types were created for this project; stochastic lithofacies, deterministic, and stochastic composite. A comparison was made between each modeling method (Table 1). Stochastic lithofacies and deterministic models are controlled only by well data therefore interwell regions are inferred and the resulting realizations may not reflect exact geologic features within the reservoir. Stochastic composite models that are conditioned to both well and seismic data provide the most geologically reasonable representations of lithofacies continuity.

Table 1: Comparison of model types

\begin{tabular}{|c|l|l|l|}
\hline Model Type & \multicolumn{1}{|c|}{$\begin{array}{c}\text { Characteristics/ } \\
\text { observations }\end{array}$} & \multicolumn{1}{|c|}{ Advantages for use } & \multicolumn{1}{|c|}{ Disadvantages for use } \\
\hline Stochastic & $\begin{array}{l}\text { Shows some } \\
\text { interconnectivity; some } \\
\text { lateral and vertical } \\
\text { distributions }\end{array}$ & $\begin{array}{l}\text { Incorporated geologic } \\
\text { information from cores and } \\
\text { outcrops; some lateral extent } \\
\text { of lithofacies can be identified }\end{array}$ & $\begin{array}{l}\text { Works best in small study } \\
\text { areas; needs lots of } \\
\text { closely spaced wells to } \\
\text { characterize heterogeneity }\end{array}$ \\
\hline Deterministic & $\begin{array}{l}\text { Continuous scaled } \\
\text { gamma-ray and density } \\
\text { distributions }\end{array}$ & $\begin{array}{l}\text { Deterministic density models } \\
\text { are useful in characterizing } \\
\text { seismic response; Models } \\
\text { ray logs would be useful in } \\
\text { identifying some geologic } \\
\text { features }\end{array}$ & $\begin{array}{l}\text { Does not incorporate } \\
\text { geologic interpretations; } \\
\text { does not incorporate } \\
\text { lithofacies so no } \\
\text { heterogeneity can be } \\
\text { seen. }\end{array}$ \\
\hline
\end{tabular}




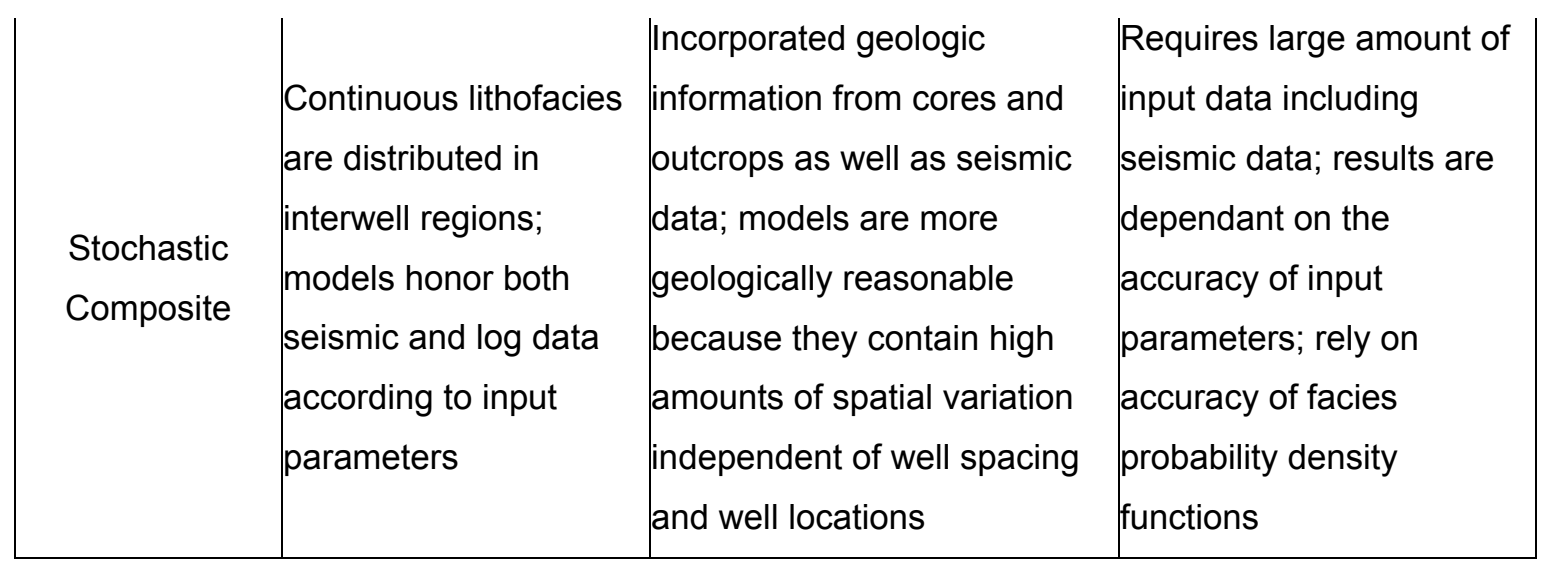

\section{$\underline{\text { Integration }}$}

Integration involves combining separate and distinct components in an effort to obtain results that are more accurate and reducing uncertainty that would have existed using only a portion of the data. While geologic models at Coalinga field include a wide range of geologic information collected from well logs, core and outcrop studies, uncertainties still exist related to the interpolation process that occurs between wells. Similarly, the current resolution in seismic data is inadequate in characterizing smallscale reservoir heterogeneities, which cannot be traced directly. Instead, their statistical properties are inferred from the seismic data. In addition, within the Temblor Formation the seismic character of the bounding surfaces is subtle and may be overlooked.

The process of integrating geologic and seismic data does not follow a clear set of methods. Instead, it involves several steps or processes that work to incorporate the two data sets. This includes the creation of stochastic composite models, the use of seismic horizons to create modeling grids, and the use of well data in the selection of bounding surfaces on seismic traces.

The best example of integration in this study was by the creation of stochastic composite models. These models use well log data and conditioned the placement of lithofacies bodies using seismic attributes and facies probability density functions. The models are useful in characterizing interwell regions because they provide stochastic representations of these areas and show the continuation of bodies that is not visible in the lithofacies models that contain no seismic data.

Other examples of integration include the selection of bounding surfaces in SMT, which is a highly integrative task that uses geologic data from core and outcrop studies, 
well logs and their interpretations, synthetic seismograms, and seismic structure maps to interpret the location of the surfaces on seismic traces.

\section{Applications to Other Field Areas}

Each reservoir is unique: physically, economically, and conceptually. Therefore choosing the most economical methods of reservoir characterization requires understanding the complex interrelationships between seismic estimates of reservoir properties. It is important that reservoir models incorporate as much data as possible in order to get a complete characterization of small-scale heterogeneities.

West Coalinga field is unique in that large amounts of well, seismic, cores, and outcrop data are available for study. However, in areas where high quantities of data are not available it would still be possible to use many of the methods that were used in this study to obtain representations that distinguish many interwell features.

Stochastic composite models can be created whenever facies log data and seismic data are available. However, the model results are dependant on the probability density functions and selection of proper interval spacing is important. 

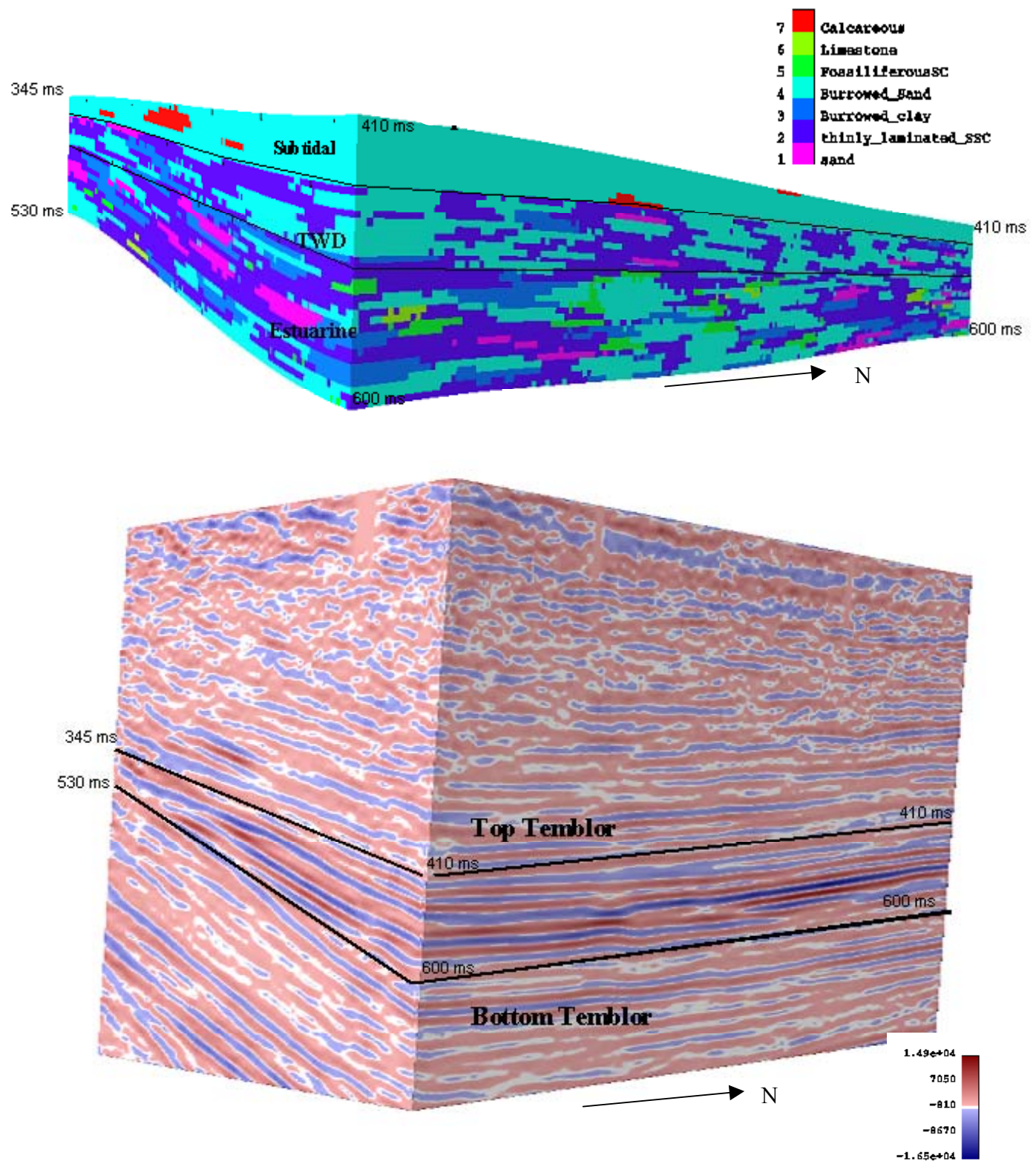

Figure 1: Illustration demonstrating scale differences between the stochastic composite model conditioned to instantaneous amplitude data for study area 2, and raw seismic data cube displaying instantaneous amplitude. $40 \mathrm{~ms}=100 \mathrm{ft}$. 